\section{UNA IDEA RECURRENTE: REFLEJOS DEL IBERISMO EN LA PRENSA ESPAÑOLA (1982-2011)}

\author{
Beatriz Peralta García \\ Facultad de Filosofía y Letras \\ Universidad de Oviedo \\ bperalta@uniovi.es
}

\begin{abstract}
Cómo citar este artículo/Citation: Peralta García, B. (2014). "Una idea recurrente: reflejos del iberismo en la prensa española (1982-2011)". Arbor, 190 (766): a120. doi: http://
\end{abstract} dx.doi.org/10.3989/arbor.2014.766n2012

Recibido: 11 octubre 2012. Aceptado: 31 marzo 2014.

RESUMEN: Desde mediados del siglo XIX las relaciones entre España y Portugal han venido estando marcadas por la idea del iberismo. Culminado el proceso de transición política en ambos países en el último cuartel del siglo XX se impone con fuerza la necesidad de sustituirla por el concepto de cooperación al amparo que ofrece la pertenencia de ambos Estados a la Unión Europea como ente supranacional de resolución de conflictos. En este artículo analizamos la presencia del iberismo en la prensa española desde principios de los años 80 hasta la primera década del siglo XXI y su particular evolución acompañando los cambios políticos, económicos y sociales del país.

PALABRAS CLAVE: España; Portugal; historia contemporánea; iberismo.

\section{A RECURRING THEME: REFLECTIONS OF THE IBERIANISM IN THE SPANISH PRESS (1982-2011)}

Copyright: (c) 2014 CSIC. Este es un artículo de acceso abierto distribuido bajo los términos de la licencia Creative Commons Attribution-Non Commercial (by-nc) Spain 3.0.

ABSTRACT: The idea of Iberian federalism has been a key feature of the relationship between Spain and Portugal since the 19th century. But in the wake of the political transitions in both countries in the late 20th century, it became necessary to replace the initial idea of Iberian federalism with the concept of cooperation in the context of their membership of the European Union as a supranational organism for the resolution of conflicts. This paper examines the presence of Iberian federalism in the Spanish press since the early 80 s until the first decade of the 21st century. In addition we explore how the concept has developed and how it influences the political, economic and social changes of the country.

KEYWORDS: Spain; Portugal; modern history; iberian federalism; present.

“Cuenta el primer ministro portugués Durão Barroso que un buen día uno de sus hijos le dijo: «Papá, quiero ir a ver a Oasis. ¿Dónde?, le preguntó. En Salamanca». Y se quedó maravillado, porque en sus tiempos de mozo viajar a España era "como ir al fin del mundo"".

(La Gaceta Regional, 2004) 


\section{REPENSANDO EL IBERISMO: PORTUGAL Y LOS GOBIERNOS SOCIALISTAS (1982-1996)}

En marzo de 1983 Raúl Morodo escribía en el diario El País: “(...) no se pueden entender las relaciones hispano-portuguesas, a nivel cultural o político, sin referirse a este ismo ideológico, que atrae y repele, que concita adhesiones y rechazos" (Morodo, 1983a). Hablaba del "iberismo" y su afirmación a principios de la década de los 80 , solo unos pocos meses después de la victoria electoral del PSOE en octubre de 1982, se enmarca en la política de reconstrucción de las relaciones bilaterales con Portugal en los años previos a la entrada de ambos países en la antigua Comunidad Económica Europea (Pereira Castañares, 1998, 989999), cerrado ya el proceso de transición política a la democracia ${ }^{1}$. En su discurso de investidura como presidente del Gobierno Felipe González había aludido a la necesidad de "fortalecer y profundizar nuestras relaciones con los países vecinos: Portugal, Francia y los países del Magreb", que en el caso especial de Portugal debían contemplarse desde una perspectiva "realista" basada en "la amistad y la cooperación", entre otros objetivos en el diseño de la política exterior del primer gobierno socialista (Cortes, 1982). En meses posteriores diferentes artículos periodísticos (Schwartz, 1983; El País, 1983a; Morodo, 1983b; Blanco Tobío, 1983) escritos tanto por quienes, de forma más o menos directa, se veían involucrados en las conversaciones como desde la misma prensa habían denunciado la necesidad de superar la distancia histórica entre ambos países divulgando este concepto junto a otros: Hispanoamérica, Iberoamérica, Latinoamérica, Hispanidad, Hispanismo, Iberoamericanismo..., una variedad de etiquetas producto de la expresión de un nuevo tiempo político, social y cultural que buscaba redefinir las relaciones internacionales de España dentro de lo que se consideraba su espacio geopolítico y cultural natural (Morán, 1990, 166-170, 411-412, 459-461; Yánez-Barnuevo, y Viñas, 1992, 92, 94). Para el caso concreto de Portugal Morodo subrayaba además la persistencia de este concepto pese a haber evolucionado notoriamente a finales del siglo XX y carecer de la acepción y las connotaciones históricas e ideológicas que lo habían definido sobre todo a lo largo del siglo XIX ${ }^{2}$. A principios de la década de los 80 aparece como una forma de referirse a los dos países que, de forma conjunta, integran mayoritariamente la península Ibérica superando el anacronismo de la unión o anexión política y sustituyéndola por la de la relación entre iguales, independientemente del contexto en el que esta se establezca. Un modo de alejar cualquier recuerdo del pasado suavizando el contenido semántico de una expresión siempre sensible a provocar suspicacias. El mismo Raúl Morodo, en un discurso pronunciado a principios de ese mismo año durante una reunión en Lisboa de portugueses y españoles para hablar de "El papel de la cultura en la sociedad democrática", había tenido mucho cuidado a la hora de referirse a las relaciones hispano-portuguesas señalando que había que "preparar un neoiberismo sobre nuevas bases" (Guardiola, 1983).

Normalizar bajo el signo democrático las relaciones con Portugal era también una exigencia impuesta por la CEE como paso previo para la integración conjunta de la península Ibérica en el marco europeo concretado en lograr un régimen transitorio especial además de consensuar la redacción de los instrumentos de adhesión (Marín, 2001b, 366). Las bases de esta normalización se habían logrado durante la visita del rey Juan Carlos I a Portugal en 1978 para ratificar un Tratado de Amistad y Cooperación entre los dos países con la mirada puesta en la integración europea. En el preámbulo se fijan los principios que debían presidir las relaciones hispano-portuguesas en lo sucesivo: "fortalecer los vínculos de amistad que ya existen, con el firme apoyo en una comunidad de sentimientos y de intereses y en una identidad nacional propia y peculiar de cada una de las altas partes contratantes, dentro del contexto europeo en el que esperamos integrarnos" (Juan Carlos I, 1978; también Jefatura del Estado, 1978: 12443-12444).

Bajo este marco político se celebraría la primera reunión oficial durante los días 11 y 12 de noviembre de 1983. Según publicaba la prensa tres eran los problemas en los que las posturas parecían más distantes: el convenio pesquero, el desequilibrio comercial a favor de España y la posible conversión en almacén nuclear de la base de Beja, descartada desde Portugal. En la entrevista que Mário Soares concede a El País (El País, 1983b) el mandatario portugués analiza con realismo la situación de España y el estancamiento de sus negociaciones producto del bloqueo impuesto por Francia al menos desde 1980, las consecuencias derivadas de la incorporación de Gran Bretaña y su contribución a los fondos comunitarios, y la situación de Grecia que, en este contexto, pretendía renegociar su propio tratado de adhesión, firmado de una forma un tanto apresurada (Fernández Navarrete, 2001, 438 y ss) ${ }^{3}$. La negociación portuguesa, por su parte, aunque laboriosa seguía un camino mucho más fluido de forma que el primer ministro portugués podía aseverar en la entrevista concedida al director del diario español que la firma de ingreso de su país podría realizarse 
a principios de 1984; para la española, por el contrario, preveía un margen que alcanzaba hasta enero de 1986, unos plazos contemplados también desde el gobierno socialista tendentes, sin embargo, a no superar los límites de la legislatura. El periodista abordaría el debate entorno a la permanencia de España en la OTAN, la reestructuración del sistema económico de los dos países y la posición de las Fuerzas Armadas en la recién consolidada democracia portuguesa. Sin embargo, desde la perspectiva española era importante intentar esclarecer los motivos de Portugal para negarse a desarrollar una negociación conjunta. Mário Soares lo argumentaría por los temores de su país a resultar penalizado por las dificultades de España -como el propio Felipe González había señalado-. Nuevamente la idea del "iberismo" y de lo "ibérico" salpica la conversación pero el mandatario portugués se mostraría tajante a la hora de definir las relaciones luso-españolas bajo un concepto que el imaginario portugués consideraba, por lo menos, un tanto ambiguo: "(...) ibérico es un todo que no implica dos naciones, cuando en la península hay dos países que la integran desde siempre: uno se llama España, y otro Portugal”. Y concluye: “(...) España no puede olvidar que Portugal tiene razones históricas para sentir desconfianza. Yo creo que esto es algo pasado y no está justificado en modo alguno, pero para superar esta desconfianza es preciso tener prudencia y no usar fórmulas demasiado imaginativas".

La firma el 12 de junio de 1985 de los Tratados y Actas de Adhesión de Portugal y España a las Comunidades Europeas (Jefatura del Estado, 1986: 3-687) redefinirá las relaciones entre los dos países regulándolas dentro de una estructura supranacional. A partir del 1 de enero de 1986 entrarán en una nueva fase política y jurídica pero el rechazo al adjetivo "ibérico" continúa entre las autoridades portuguesas que con motivo de la cumbre bilateral de Guimarães los días 24 y 25 de octubre de ese mismo año deciden denominarla "luso-española". La prensa acogería sus resultados con una impresión desigual. Si los rotativos españoles no dudaron en considerarla un éxito los portugueses, por el contrario, se sintieron algo decepcionados por lo que consideraban un balance positivo únicamente para los intereses de España (Ferro, 1986, 21). Un año más tarde, el 14 de diciembre de 1987, con motivo de la primera visita oficial de Mário Soares ya como presidente de la República Portuguesa a España donde, entre otros actos, sería investido Doctor Honoris Causa por la Universidad de Salamanca ${ }^{4}$, Raúl Morodo verá el comienzo de la superación de viejos tópicos:
"Esta visita de Estado, entre un rey que habla portugués y fue trasterrado, y un presidente republicano que habla español y conoció exilios, tiene una connotación singular: servir de base para un nuevo iberismo democrático, con integración europea y proyección ultramarina. Frente a caducos iberismos, con aspiraciones hegemónicas o imperialistas, frente al iberismo y contra-iberismos que solapaban una reducción cultural y política, frente a las distancias impuestas por las dictaduras, Portugal y España, países plenamente europeos. Sin dejar de ser ibéricos e iberoamericanos, pueden y deben relanzar una cooperación eficaz, que aleje las dictaduras y aproxime las identidades" (Morodo, 1987).

La Universidad de Salamanca recibiría, junto a la de Coimbra, el Premio Príncipe de Asturias de Cooperación Internacional en 1986 por "la extraordinaria aportación que ambas han prestado a la formación del espíritu de todos los países que integran la Comunidad iberoamericana y a su diálogo tradicional con las universidades de las Américas, que convirtió el Atlántico en Mare Nostrum de la cultura universal", según consta en el acta del jurado reunido en Oviedo los días 29 y 30 de mayo de ese año (www.fpa.es).

Al margen de apreciaciones personales hay que subrayar que junto a la incorporación del discurso cultural en la voz, por ejemplo, de Fernando Pessoa y su pensamiento iberista recordado por los intelectuales españoles (Morodo, 1985b; 1985a; 2005) y la celebración en Madrid de una exposición dedicada al arte portugués (Morales y Marín, 1985, 36), este intercambio de visitas hace posible la recuperación de la presencia de Portugal en España, muchas veces desde la repetición incansable de tópicos que se prolonga a lo largo de los años (Morales y Marín, cit; Llamazares, 1987; Landero, 1991; Villena, 1997; El País, 1999; Martínez, 2000; Petschen, 2006; Yáñez, 2007; Gibson, 2007), pero también devolviendo al público español de finales del siglo XX los autores portugueses ${ }^{5}$. La traducción al español de las obras de José Saramago, en especial La balsa de piedra (Saramago, 1987b) ${ }^{6}$, que aborda la fábula de una península Ibérica a la deriva tras desprenderse del continente europeo fue, probablemente, el inicio de la difusión en España de la literatura portuguesa contemporánea ${ }^{7}$, posibilitó la reedición de sus clásicos ${ }^{8}$ y, en el terreno personal, llevó a la internacionalización del autor, lo que a la postre se traduciría en la concesión del Premio Nobel en 1998.

Pero las relaciones hispano-portuguesas continuarán girando, como en el siglo XIX, entorno al debate recurrente del iberismo, nunca olvidado y siempre presente con una regularidad cíclica. Volverá a apa- 
recer, tímidamente, de la mano de Gregorio Salvador en un artículo publicado en $A B C$ con motivo del encuentro de escritores, profesores y críticos literarios de España y Portugal en la primera semana de febrero de 1988:

\begin{abstract}
"Vivimos en una península -palabra que quiere decir "casi isla», escribe- (...). Ése es nuestro ámbito y en el que tenemos que habitar y que movernos. No le pongamos puertas al campo y considerémonos lo que evidentemente somos: una unidad geográfica casi enteramente rodeada de mar y un secular amasijo de pueblos que fueron llegando sucesivamente a este confín occidental y dejando en él su semilla. Y luego bien mezclados y revueltos, capaces de llevar ese confín a través del Atlántico, mucho más allá, hasta las costas americanas del Pacífico" (Salvador, 1988).
\end{abstract}

Un mes más tarde la prensa publicaba, sobrecogida, el incendio que destruyó el emblemático Chiado lisboeta. Desde el editorial de $A B C$ se instaba incluso al gobierno español a habilitar los medios necesarios para contribuir a su reconstrucción argumentando las seculares relaciones entre ambos países sustanciadas en una denominada "tradición intelectual hispanoportuguesa: el iberismo": "Puesto al día, -decía $A B C$ en su editorial- el iberismo significa hoy ahondar en los lazos culturales e históricos que unen a los dos pueblos. La reconstrucción de Lisboa debe servir para acelerar el necesario proceso de buen entendimiento peninsular, el diálogo continuo y abierto entre ambas naciones. Este proceso debe estar por encima de las contingencias políticas (...)" $(A B C, 1988,11)$.

Hasta este momento las referencias al iberismo se habían circunscrito a los esfuerzos de Portugal por mantener visible su individualidad dentro del ámbito de sus relaciones bilaterales con España, pero a finales de la década de los años 80 reaparecerá el fenómeno de las encuestas de opinión que con cierta regularidad pulsan el sentir popular sobre este tema, a veces con inusitada virulencia, en algunos sectores de la prensa portuguesa. Así sucederá en 1989 cuando entre enero y junio España ostente, por primera vez, la presidencia de turno de la Comunidad Económica Europea. Las iniciativas que el gobierno socialista de Felipe González promovió hacia Portugal durante el semestre de su presidencia ocasionaron el enfado del director del semanario $O$ Independente, Manuel Esteves Cardoso, que alertaría de la excesiva presencia de las empresas españolas en Portugal y, como correlato, temía que el potencial cultural español acabase imponiéndose hasta el punto de oscurecer la referencia europea. El periodista -que ya había abordado con humor el tema del iberismo algunos años atrás con motivo del son- deo de otro periódico, Expresso, que aseguraba que el $26 \%$ de los portugueses deseaba una unión política con España ${ }^{9}$ (Cardoso, 1990, 124-125)- lo ejemplifica con el siguiente argumento: "La mayoría de los juguetes de mis hijas proceden de España. Pues bien, los otros países traducen las etiquetas o las instrucciones cuando introducen sus productos en Portugal. Los españoles no traducen. Esto es solo un ejemplo de lo que queremos expresar cuando hablamos de un peligro de pérdida de independencia". Y admitía que existía un "iberismo" -entendido como anexionismolatente en amplios sectores de la sociedad portuguesa animados por el potencial económico de España y su mayor nivel de vida (M. R., 1989).

En España la prensa recibió el ataque con estupor: "Si no hay más cera que la que arde, ¿qué sentido tiene reeditar el fantasma del asimilacionismo español? ¿Acaso porque algunas señoras lean el iHola! en las peluquerías o en los asientos de primera clase en el tren?" (Idem), se preguntaba el corresponsal de EI País en Lisboa. Los diarios más conservadores, por su parte, no dejarían de saludar el acercamiento (Fonseca, 1989, 60) a Portugal interpretándolo como "un nuevo iberismo" aunque con el cuidado de ceñirlo a un ámbito estrictamente cultural: "Parece claro que el iberismo ha de entenderse hoy como un fenómeno cultural, de signo regional, que debe incluirse en el más vasto sistema europeo. Defender una presunta identidad ibérica al margen de Europa resulta un anacronismo" ( $A B C, 1989 \mathrm{~b}, 31)$ escribe $A B C$ en su editorial de 6 de junio. Es precisamente con el título de "Un nuevo iberismo" con el que en un editorial anterior este diario se había referido a la segunda visita de Estado de los reyes de España a Portugal y la investidura del rey Juan Carlos como Doctor Honoris Causa por la Universidad de Coimbra el 17 de mayo de ese mismo año. Ya en 1985 el columnista José Luis Morales y Marín había recordado en el mismo periódico el apoyo prestado por Portugal a la causa del conde de Barcelona al permitirle instalarse en Estoril durante los años de la dictadura franquista (Morales y Marín, cit.). En el texto $(A B C, 1989 d, 31)$ se volverá a aludir al exilio de $D$. Juan y su familia en tierras portuguesas pero el rey, sin embargo, tanto en el discurso pronunciado en la Assembleia da República como en su agradecimiento a la institución universitaria (Juan Carlos I, 1989b), ambos expresados en portugués, prefirió recordar ante el presidente Mário Soares, que interrumpió su tratamiento médico para acompañarlo en Coimbra ${ }^{10}$, la conveniencia mutua de los intercambios comerciales, la pertenencia a los órganos internacionales de seguridad (OTAN), la gestión conjunta, desde la respon- 
sabilidad, del mismo espacio geográfico y la herencia histórico-cultural del país vecino, destacando el marco común europeo como referencia supranacional al que se subordinan las relaciones hispano-portuguesas. "Nuestras dos naciones -afirmó el rey ante los diputados portugueses- no tienen, por consiguiente, ninguna excusa para olvidarse la una de la otra. La realidad política, las perspectivas económicas, los proyectos culturales, nos empujan a una constante colaboración en la que se respeten las particularidades propias de cada país" (Juan Carlos I, 1989a).

Un mes después España cerraba su semestre de presidencia con la celebración en Madrid, entre otros actos, de un encuentro entre escritores de ambos países promovido por el Ministerio de Cultura a través del Centro de las Letras Españolas y el Instituto Português do Livro e da Leitura. Se denominó "Jornadas de Literatura Portuguesa" y se desarrolló entre los días 6 a 11 de junio en el Círculo de Bellas Artes. Entre los jóvenes autores portugueses invitados se deja percibir una cierta antinomia latente entre los que se declaran abiertamente no iberistas, como la novelista Luisa Costa Gomes, y el poeta y novelista Francisco José Viegas, que se afirma "tímidamente", es adjetivo del periodista, "iberista" (El País, 1989). Para los intelectuales españoles, por el contrario, el iberismo continuará exento de las connotaciones asimilacionistas que provoca entre sus homólogos portugueses. En las jornadas madrileñas declararon su entusiasmo y admiración por la literatura portuguesa. Gonzalo Torrente Ballester, Blanca Andreu, José Hierro y Antonio Muñoz Molina fueron algunos de los escritores que participaron en el encuentro pero las alusiones iberistas proceden de Pere Gimferrer que ve en él “(...) la prolongación de ese ideal de «iberismo» tan propio del siglo XIX y tan necesario hoy en día para dos culturas homogéneas como la nuestra y la portuguesa. Volvemos, regresamos a las raíces del iberismo" ( $A B C$, 1989a, 63). A finales de año se publicaría, por primera vez ${ }^{11}$, la traducción al portugués de la obra de Miguel de Unamuno Por tierras de Portugal y de España (1911) $(A B C, 1989 \mathrm{e}, 20)$ en una edición patrocinada por la Dirección General del Libro y las Bibliotecas del Ministerio de Cultura español (Unamuno, 1989).

La década de los noventa marca el inicio de los éxitos políticos de la diplomacia española a nivel internacional con un año clave: 1992. En ese año acabaría para España el período transitorio previsto en el Tratado de Adhesión y culminaba el proyecto de integración comunitaria del Acta Única. Festejó el $V$ Centenario del Descubrimiento de América, se celebraron en Barcelona los XXV Juegos Olímpicos y Sevilla acogió la Exposición Internacional (abril a octubre) (Cortes Generales, 1986). En los dos últimos casos las inversiones en las ciudades supusieron la reestructuración de la malla urbana y la rehabilitación del patrimonio histórico, entre otros logros, y la inversión en infraestructuras se concretó en la entrada en funcionamiento del tren de alta velocidad (AVE) en la línea Madrid-Sevilla. España empieza a cooperar con fuerzas internacionales en la guerra del Golfo Pérsico (1991) y en la de Bosnia (1992); impulsa en Madrid la Conferencia Internacional de Paz sobre Oriente Medio (1991) y en el ámbito cultural consigue para esta la designación como Capital Cultural Europea al mismo tiempo que Santiago de Compostela celebra el Año Jacobeo. Por último, España empieza a ser donante de ayuda al desarrollo con la creación en 1985 de la Secretaría de Estado para la Cooperación Internacional e Iberoamérica, que en 1988 reestructura las diferentes instituciones de este ámbito en la Agencia Española de Cooperación Internacional (AECI). En diciembre de 1991 este proceso culmina con el acceso al Comité de Ayuda al Desarrollo de la OCDE (Cortes Generales, 1989).

En este contexto se celebra, a principios de 1990, la tercera cumbre hispano-portuguesa (Sevilla, 2 y 3 de febrero) con un contenido eminentemente económico. Así lo subrayaría el profesor Velarde Fuentes en un artículo publicado en $A B C$ donde sintetizaba la historia de las relaciones económicas de España y Portugal desde el siglo XIX. Lo titulaba significativamente "La unión económica ibérica" (Velarde, 1990) para demostrar que las pretensiones de un zollverein ibérico carecieron de apoyos decididos a pesar de la articulación de diversos proyectos políticos y económicos hasta que la integración de ambos países en la CEE venga a crear el marco jurídico adecuado para alcanzar la construcción de aquella unidad económica tantas veces anhelada. En la agenda de las delegaciones los temas a tratar fueron las relaciones transfronterizas, las comunicaciones y los transportes. Solo el proyecto del gasoducto ibérico parecía poner la nota discordante al desarrollo de unos contactos que desde la primera cumbre de 1986 se habían traducido en logros concretos. El columnista Jesús Fonseca los enumera: "coordinación de planes, análisis de peticiones conjuntas, de financiación comunitaria, que han sido bien acogidas por Bruselas" (Fonseca, 1990, 80). Aníbal Cavaco Silva, a la sazón primer ministro, quitaba hierro a las posibles dificultades: "Nos interesa a Portugal y a España aproximar criterios y posiciones dentro del marco de defensa de nuestros intereses, porque es vital para el 
desarrollo de los dos países y sobre todo en nuestras zonas fronterizas. (...) Entre Portugal y España no hay en estos momentos problemas aparentes, y si existe algún desacuerdo lo resolveremos" ( $A B C, 1990 a, 81)$. El editorial de $A B C$ minimizaba tanto la cuestión del gasoducto como la gestión conjunta de los ríos frente a lo que consideraba la gran amenaza para los intereses de ambos países: la reestructuración de Europa tras la caída del muro de Berlín, ya que una eventual ampliación hacia los países del Este conllevaría no solo el debilitamiento del centro de gravedad político desde el sur hacia el norte sino, sobre todo, la disminución de los fondos comunitarios destinados a corregir el desequilibrio económico tradicionalmente padecido por los países meridionales. Y en un tono un tanto apocalíptico, concluía:

“(...) la unidad sincera entre Portugal y España, que siempre fue deseable y útil, resulta en estos momentos sencillamente indispensable. Siempre debimos estar juntos, aunque durante tiempo viviésemos de espaldas los unos a los otros. (...) No hace falta resucitar el tópico del iberismo que levanta entre nuestros vecinos un histórico malestar sino, más sencillamente, ponernos a trabajar unidos para defendernos juntos. Las amenazas sobre las dos naciones son ciertas e idénticas" ( $A B C, 1990 \mathrm{~b}, 19)$.

\section{EL IMPULSO CULTURAL}

A lo largo del epígrafe anterior hemos aludido al interés de ambos países por fomentar sus relaciones culturales. Ya desde la primera reunión bilateral de 1983 Mário Soares apuntaba la necesidad de incluir acuerdos en este ámbito junto a materias como tecnología, turismo, ferrocarriles, fronteras, pesca y comercio (El País, 1983b, cit.), un aspecto que, a pesar de los esfuerzos realizados, todavía en 1990 venía siendo reclamado con insistencia también desde la prensa española:

\footnotetext{
"No se puede abandonar todo a los contactos personales entre escritores, al interés particular, por cierto cada vez mayor, desde diferentes posiciones de portugueses y españoles, por la historia y las letras del vecino. Tienen que hacer algo más los Gobiernos de Lisboa y de Madrid. Algo como fortalecer sus programas de becas, multiplicar los lectores de una u otra lengua en las Universidades de allá y de acá, dedicar más fondos a la investigación histórica, multiplicar las exposiciones, los encuentros, las coproducciones que no se hacen para el cine y la televisión y que podrían hacerse; los centros culturales que ni siquiera existen, los que siempre están a punto de abrir y nunca abren" (Fonseca, 1990, 81).
}

Desde los inicios de la década de los años 80 las páginas de los diarios españoles habían comenzado a incluir, al principio de manera más modesta ${ }^{12}$, reflexiones y noticias entorno a figuras hegemónicas del panorama cultural portugués del siglo XX directamente relacionadas con España: Fernando Pessoa (Crespo, 1985b; 1985a), Natalia Correia ${ }^{13}$, José Saramago, Miguel Torga y José Cardoso Pires (Villena, 1997) son algunos de los nombres con los que se empieza a familiarizar al lector, que se completa con la difusión de iniciativas surgidas en el mundo académico. Son noticia, por ejemplo, la publicación en Cáceres de la revista bilingüe Espacios / Espaços escritos (1987) (Jara, 1987; Crespo, 1985b, 1987; Landero, 1991), la celebración en la Universidad de Salamanca de unas jornadas dedicadas al centenario de la muerte del novelista Camilo Castelo Branco (1990) (ABC, 1990c), y junto a la Universidade Lusófona de Humanidades e Tecnologias de Castelo Branco, de la IIa Semana Cultural en 1994 (ABC, 1994a). Se trata de un cambio cualitativa y cuantitativamente notable pero desde Portugal, sin embargo, se tiene la percepción de que esta presencia es residual cuando no abiertamente excepcional, y no solo restringida al plano cultural, también en el político. En una entrevista realizada en 1992 al director de un periódico señero en la historia de la prensa portuguesa, Diário de Notícias, -su fundación se remonta a 1864- Dinis Abreu afirmaba: "Resulta mucho más frecuente encontrar noticias sobre España en la Prensa portuguesa que lo contrario. Es muy habitual que «Diario de Noticias» informe acerca de una visita del Rey Juan Carlos o de unas declaraciones de González, cosa que no sucede con los periódicos españoles respecto a los asuntos portugueses. Lo primero es casi diario, lo segundo, raro" (Acuña, 1992, 64-65).

El punto de inflexión lo marcarán dos acontecimientos importantes en el mundo de la cultura portuguesa: el fallecimiento del poeta Miguel Torga en 1995 y, sobre todo, la concesión en 1998 del Premio Nobel de Literatura a José Saramago, pues traerán el Portugal culto a la vida cotidiana de los españoles. Como antecedentes, aunque desde una perspectiva mucho más divulgativa del país como referencia territorial, habría que señalar el estreno en 1995 de la película de José Luis García Sánchez titulada Suspiros de España (y Portugal), una comedia protagonizada por Juan Echanove y Juan Luis Galiardo cuyo sentido su director explica con estas palabras:

"Era una historia que iba a transcurrir por un camino y en España tenemos dos caminos posibles: el de Maastricht y Europa y el que se dirige hacia nosotros mismos, la Península Ibérica. Nosotros, por supuesto, 
elegimos el último, ese que responde al terreno poético hispánico, a la cultura nacida de unos sentimientos que se expresan a gritos, unos sentimientos que proceden del hambre y de la falta de libertades. En definitiva, la poética de los sobrevivientes, que es lo que somos todos los ibéricos" (García, 1995).

Y la publicación, ya en 1998, de la novela de Julio Llamazares Tras-os-Montes (Pulido, 1998, 49).

La presencia de Torga en las páginas de los diarios españoles se detecta en 1991 cuando el suplemento cultural de $A B C$ publica una entrevista con él bajo el título: "El iberismo inalterable de Miguel Torga"14. El poeta entonaba en aquella ocasión un canto apasionado de España y de la cultura española:

\footnotetext{
"Yo he meditado mucho sobre el fenómeno portugués y sobre el fenómeno español -le explica Torga al periodista José María Moreiro-. Me he sentido y me siento muy atraído por España. Yo he llegado a ir a Madrid solo para ver el "Guernica» cuando lo trajeron. He viajado por todo el país de norte a sur. La cultura española es la única auténticamente viva y creadora que queda hoy en Europa, porque no encarna un acto frío sino una gran sinceridad y grandeza por su carácter. Admiro, incluso, la guerra de España, porque fue una guerra limpia y noble, en la que lucharon unos contra otros con gallardía y nobleza. Demostraron un coraje y una entereza totales, a pesar de la crueldad que tienen todas las guerras, porque fue en defensa de unos ideales, y no como otras guerras, más crueles, y frías y recientes. Claro que también he de referirme a los horrores que tuve ocasión de observar al natural. Todavía me duelen en la carne y en el alma. Traumatizaron indeleblemente a toda mi generación" (Moreira, 1991, IX).
}

En 1995 la misma prensa hubo de recoger la noticia de su fallecimiento, con casi absoluta coincidencia en los titulares pero con una diferencia significativa de matices en el subtítulo. Si el progresista El País prefirió ceñirse estrictamente a su vertiente literaria, el conservador $A B C$ resalta su oposición a la dictadura salazarista abordando el impacto de su obra en páginas posteriores ${ }^{15}$. De la entrevista concedida en 1991 el diario rescata ahora una confesión estremecedora: la de la destrucción de su obra inédita. Oigamos a Torga: “(...) nunca quise verme momificado y póstumo (...). Ser y sentirme vivo es lo que me importa. Puede ver las palabras que figuran al frente del manuscrito que estoy escribiendo y que constituirá el tomo XVI de mi «Diario»: "Para ser destruido si muriera de repente». Confío en mi mujer". El periodista pregunta:

“-Destruir su obra ya escrita. ¿Por qué?

-Ya he repetido -responde Torga- que, para mí, la creación es un acto sagrado. No quiero que sea pu- blicado ningún inédito mío después de que yo muera. No quiero que nadie manipule mi obra, porque una obra es una estructura única y total. Cuando yo muera, mi obra habrá acabado también, y quedará completa con lo editado por mí hasta ese momento" (Moreira, 1995, 49).

El periódico tuvo la oportunidad de incluir las reflexiones de Saramago, Nuno Júdice -que también aludía en su texto a Antero de Quental y a Luis de Camões, a los Descubrimientos portugueses y a la batalla de Alcácer-Quibir-, Eduardo Lourenço y Basilio Losada sobre el autor, además de presentar una síntesis cronológica de su obra ${ }^{16}$. En 2007 la prensa se haría eco de la conmemoración del centenario de su nacimiento (Salgado, 2007).

Visto con una cierta perspectiva, 1998 es un año significativo para la historia cultural reciente de Portugal y de España. A nivel interno se vivió la experiencia internacional de la organización de la Exposición Mundial que, como en el caso de Barcelona y Sevilla, permitiría la reestructuración y modernización de Lisboa, descubierta desde el punto de vista turístico por los miles de españoles que la visitaron ${ }^{17}$. En España los festejos del 98 contarán con la colaboración ministerial a través de la creación de la Sociedad Estatal Lisboa 1998, dependiente del Ministerio de Cultura (a partir de 2002 bajo la denominación de "Sociedad Española de Conmemoraciones Culturales") que promovió la realización de diferentes encuentros, seminarios y coloquios en España y en Portugal ${ }^{18}$. Además, el centenario de la crisis del 98 provocará la confluencia de varios elementos: por un lado, Cataluña repensará su relación con dos realidades políticas diferentes, España y Portugal, con una mirada puesta en el iberismo ${ }^{19}$; por otro, la concesión del Premio Nobel de Literatura de ese año a José Saramago funcionará como un nexo cultural entre los dos países, e introducirá de forma definitiva la presencia de la literatura portuguesa en el imaginario cultural español ${ }^{20}$. El premio se vivió casi como algo propio -con las oportunas matizaciones-y de igual manera se interpretará su fallecimiento en junio de 2010 (Jurista, 2010). En su crónica sobre la concesión del Nobel Miguel García-Posada escribía:

“(...) la obra de Saramago está perfectamente divulgada en España y el escritor, unido a nuestro país por vínculos diversos, incluido el territorial de su residencia en Lanzarote, ha hecho popular su figura entre nosotros, donde algunas de sus obras han alcanzado repercusión sobresaliente. La Academia no ha concedido esta vez su premio de literatura a un escritor extranjero. Pepe Saramago es, en cierto sentido, uno de los nuestros aunque sea, sobre todo, portugués" (García-Posada, 1998). 
En efecto, la profesión de iberismo de la que hacía gala el autor, su residencia en España, su matrimonio con una española, la periodista Pilar del Río, y ser una figura habitual en el panorama literario español, habían convertido a Saramago en un autor "de casa" de cara al público y él mismo remarcaba con énfasis todas estas realidades: "Soy hijo de Portugal, pero soy hijo adoptivo de Castril, una localidad de Granada, y también de Lanzarote, de modo que soy andaluz y canario. Creo que tenemos que acercarnos unos a otros por encima de las diferencias" (De León-Sotelo, 1998, 47; también Conte, 1998, 57; Márquez Reviriego, 1998, 30).

A partir de 2000 la cultura portuguesa, en casi todas sus modalidades, se consolida en el panorama intelectual español tras la organización de "Perfil de Portugal" promovido por Luís Neto, presidente del ICEP (Instituto de Comércio e Turismo de Portugal) con el objetivo de divulgar "los nombres consagrados de la cultura portuguesa en España" junto a otros menos conocidos (García, 2001c; 2001a; 2001d, 35). Al mundo de la literatura, que se amplía para dar cabida a nuevos nombres: António Lobo Antunes -cuya visión cultural coincide con el iberismo (Blanco, 2000, 7-12), según sus propias palabras, y era además colaborador habitual en Babelia, el suplemento cultural de EI País-, Lídia Jorge, João de Melo, Inés Pedrosa y José Luís Peixoto, se une el de la música. Desde intérpretes de fado como Mafalda Arnauth, Camané, Dulce Pontes y Mariza a pianistas como Maria João Pires -en 2004 se haría cargo de la sección musical de la Fundación Caja Duero-, Mário Laginha y Pedro Burmester los diferentes estilos musicales empiezan a encontrar acomodo en las salas españolas. También la arquitectura, representada en la obra de Siza Vieira y el cine, con el ciclo dedicado a Manuel de Oliveira, Pedro Costa, João Botelho, Teresa Villaverde y João Canijo, que además contaría con la presencia de los actores Joaquim de Almeida y María de Medeiros (García, 2001a). Es, además, el año en el que una coproducción hispano-portuguesa lleva a la pantalla la versión cinematográfica de La balsa de piedra dirigida por un holandés, George Sluizer, y un reparto compuesto por los actores Icíar Bollaín, Gabino Diego y Federico Luppi, del lado español, y Diogo Infante y Ana Padrão, por el portugués ( $A B C, 2001,82)$. El filósofo Eduardo Lourenço participaría con la presentación en el Círculo de Bellas Artes de Madrid de su libro editado en España con el título Europa y nosotros, una reflexión anterior a los atentados del 11 de septiembre entorno a las relaciones de Portugal con Europa. Con respecto a España Eduardo Lourenço explica que "la visibilidad de algunos autores portugueses en España y el resto del mundo es extraordinaria. Mi generación no podría imaginar ese gran progreso. (...) Nuestro problema ha sido siempre España, dentro y fuera de la Península. Somos dos culturas universales con una historia paralela y un desconocimiento mutuo por razones históricas, pero eso está cambiando" (García, 2001b).

Un año más tarde el Ministerio de Educación, Cultura y Deporte avanza en este impulso al intercambio y la difusión cultural con la institucionalización o concesión de premios a personalidades del ámbito lusófono. En 2001, por orden de 17 de julio, crea el Premio "Velázquez" de las Artes Plásticas (BOE de 25 de julio de 2001), con vocación internacional que hasta la fecha le ha sido concedido a dos artistas de habla portuguesa: al brasileño Cildo Meireles en 2008 y al portugués Artur Barrio en 2011 (De Diego, 2011). En 2002 Sofia de Mello Breyner gana la XII edición del Premio Reina Sofía de Poesía Iberoamericana, concedido conjuntamente por el Ministerio y la Universidad de Salamanca, que en 1994 ya había distinguido al poeta brasileño João Cabral de Mello Neto (Junta de Castilla y León, 2003, enero-junio, 270-272). En 2006 los gobiernos de España y de Portugal a través de sus respectivos ministerios de Cultura crean de forma conjunta el Premio "Luso-Español de Arte y Cultura". Entre sus objetivos declarados están premiar "la obra de un creador en el ámbito del arte y la cultura, en cualquiera de sus manifestaciones; (...) incrementar la comunicación artística que siempre ha existido entre el arte de España y Portugal; y (...) expresar su reconocimiento público a aquellos autores, pensadores, creadores e intérpretes que de modo más significativo contribuyan al enriquecimiento de las artes, de las letras y del pensamiento en ambos países" (Ministerio de Cultura, 2006). El premio tiene una periodicidad bianual, habiendo siendo concedido hasta la fecha al poeta José Bento (2006), al profesor Perfecto Cuadrado Fernández (2008) y al arquitecto Álvaro Siza (2010). En esta última edición el jurado decidió reconocer de manera especial la obra de José Saramago por el acercamiento y mutuo conocimiento entre ambos países, así como la labor desarrollada por instituciones fronterizas, como las iniciativas impulsadas desde la Comunidad Autónoma de Extremadura (Ministerio de Cultura, 2010).

Por otro lado hay que destacar el nombramiento, a principios de 2012, de João Fernandes, director del Museu Serralves, de Oporto, como subdirector del Museo Reina Sofía de Arte Contemporáneo (EI País, 2012). 
A la labor institucional hay que añadir la desarrollada desde los medios de comunicación. En 2005 la divulgación de la historia común de España y de Portugal llega a los hogares españoles con una coproducción entre TVE y RTP (Radiotelevisión Pública Portuguesa) dirigida por el periodista Agustín Remesal titulada "La Raya Quebrada" (Campelo, 2005). Además, Portugal como destino turístico se consolida en el mercado español. En 2008 el suplemento "El Viajero" del diario El País le dedicará dos especiales en poco más de un mes (El País, 2008a, 2008b), y otro en octubre de 2011 (El País, 2011c). En el verano de ese mismo año TVE emitirá, dentro de los telediarios de los días 31 de julio y 1 de agosto, un breve reportaje sobre los atractivos de la ciudad de Lisboa. Preguntados los españoles sobre las razones de su visita las respuestas subrayan la persistencia de los tópicos: en plena crisis financiera global los entrevistados aluden a la cercanía del país y su accesibilidad económica pero también a su desconocimiento.

A finales de la década de 2000 el mundo del deporte se sumaría a esta larga lista de iniciativas conjuntas. La buena sintonía entre Portugal y España se ha concretado en el compromiso de organización de eventos internacionales, como el Campeonato Mundial de Fútbol $^{21}$ de 2018 -que ganaría Rusia- y el de 2022, aún sin decidir. Es precisamente en este ámbito donde la imagen de Portugal se hace particularmente visible para la sociedad española, dada la presencia de jugadores portugueses pero también brasileños en la liga profesional española.

\section{EL CAMBIO DE SIGNO POLÍTICO: PORTUGAL Y LOS GOBIERNOS DE JOSÉ MARÍA AZNAR (1996-2004)}

En términos generales la llegada del Partido Popular al gobierno no supuso un cambio sustantivo de la política exterior en relación con los años de gobiernos socialistas, en especial en sus relaciones con Europa, Iberoamérica, el Mediterráneo y los países del Magreb y, en el ámbito de la cooperación internacional y la seguridad (Cortes Generales, 1996, 16-19; Marín, 2001a, 456; Martínez Lillo, 2001, 361 y ss; García Pérez, 2003, 545 y ss). Sin embargo, sí es posible señalar la presencia de una serie de cambios que, como explica Rafael García Pérez, permiten hablar de un cierto "revisionismo" (Idem, 545) en la política exterior del Partido Popular, particularmente tras la llegada de Josep Piqué (2000-2002) al ministerio. Con la aprobación del Plan Estratégico de Acción Exterior (2000) España adoptaría una posición más activa, sobre todo en el mundo empresarial e incluiría la cuenca asiática del Pacífico como prioridad estratégica. Además, en el ámbito de las relaciones bilaterales se promovería un acercamiento más estrecho a Estados Unidos (Cortes Generales, 2000, 16-17).

En septiembre de 2000 los reyes de España visitan por tercera vez Portugal tras finalizar este su semestre de presidencia europea. Como señalaría el rey Juan Carlos en la Assembleia da República el viaje se realiza cuando ambos países han llegado a un "período de madurez de nuestras relaciones bilaterales, de consolidación en el mutuo entendimiento entre nuestros dos pueblos" (Juan Carlos I, 2000). De ahí la sorpresa con la que en España se acogió el análisis del presidente Jorge Sampaio sobre las relaciones de Portugal y España en el Foro $A B C$ en el mes de noviembre $^{22}$. Sampaio consideraba que solo desde el fortalecimiento de los intercambios culturales, por su reflejo de la identidad y especificidad propia de cada país, se podría llegar a un mejor conocimiento y comprensión mutuos, y mostraba su estupor al comprobar la "desatención" con la que España ha encarado tradicionalmente la realidad histórica de Portugal. Al mismo tiempo no dejaría de referirse a lo que en el plano económico denominó la "asimetría" de la presencia española en ámbitos de la vida cotidiana de los ciudadanos portugueses en los sectores de la alimentación, la banca, los seguros, el vestuario y el inmobiliario. Si las empresas españolas habían conseguido imponerse en la realización de grandes infraestructuras, la distribución de petróleo o en los concursos de privatización tal no parecía corresponderse con la de las grandes empresas portuguesas del mismo ramo en España, por lo que llamaba a alcanzar "planos de equilibrio y proporcionalidad" a pesar de las naturales diferencias de mercado y población. El columnista de $A B C$ Eduardo San Martín entonaría entonces un apesadumbrado mea culpa sobre las relaciones hispanoportuguesas a lo largo de la historia: "el pueblo portugués es tan celoso de una nacionalidad forjada en gran medida en el no-ser España que el ser una misma cosa con nosotros les sumiría en una indigencia identitaria insoportable después de ocho siglos de historia independiente, una de las más dilatadas de Europa". Con una percepción algo tópica y distorsionada del concepto y evolución de las teorías iberistas abogaba, en una línea editorial habitual a lo largo de los años en este diario, por un iberismo de nuevo cuño, sustituto natural del promovido en el siglo XIX y los primeros años del siglo $X X$, en "algunos campos del pensamiento y la creación, y hasta en las relaciones profesionales y personales" (San Martín, 2003, 35). Sin embargo, la 19a cumbre Luso-Española, celebrada 
solo unos pocos días después de la intervención del presidente Sampaio en Madrid, despejaría algunas incertidumbres en dos aspectos relevantes para la cohesión interna de la península Ibérica: el Mercado Ibérico de Electricidad (MIBEL), a partir del 20 de abril de 2004 (El País, 2003b; Pinto, y Egurbide, 2003; El País, 2003a), y la construcción de las líneas de ferrocarril de alta velocidad ${ }^{23}$ (Oporto-Vigo, 2009; MadridLisboa, 2010; Oporto-Aveiro-Salamanca, 2015; FaroHuelva, 2018), que completaba el esfuerzo realizado por la Junta de Castilla y León y las autoridades portuguesas en el sector del transporte aéreo para unir las ciudades de Valladolid y Lisboa con enlaces diarios (Junta de Castilla y León, 2003, enero-junio, 51 y ss.), y en el de la construcción de autovías y carreteras. Es en este contexto en el que se inserta la nueva polémica iberista desatada a finales de año con la publicación de Os Espanhóis e Portugal (Antunes, 2003), de José Freire Antunes, por su análisis de la relación política de España y Portugal a lo largo del siglo XX que obligaría a Raúl Morodo a realizar nuevos esfuerzos para tratar de explicarle al lector español, desde una perspectiva histórica, la problemática del iberismo en las relaciones España-Portugal (Morodo, 2004).

\section{ACTUALIDAD DE LAS RELACIONES ESPAÑA-PORTUGAL (2004-2011)}

A partir de 2004-2005 las relaciones hispano-portuguesas entran en una nueva fase marcada por la coincidencia ideológica de los partidos en los respectivos gobiernos que habrían de gestionar el nuevo escenario internacional surgido de la crisis financiera de 2008. En España el nuevo gobierno socialista de José Luis Rodríguez Zapatero mantendrá los ejes específicos de la política exterior española de décadas precedentes fundados en un inequívoco "compromiso europeísta", una atención preferente a Latinoamérica y el Mediterráneo y el reajuste con Estado Unidos estableciendo "una relación de países socios y amigos basada en la lealtad y la franqueza recíprocas" (Cortes Generales, 2004). En la segunda legislatura estaría también orientada a ganar "peso e influencia en la escena internacional" además de incorporar el África subsahariana como nuevo foco de interés estratégico con la aprobación del "Plan África 2008-2012»" (Cortes Generales, 2008). Paralelamente la llegada de José Sócrates al gobierno portugués se traduciría en un impulso a la construcción del mercado ibérico. El periodista de El País expresaba de forma muy gráfica este nuevo sentir en su crónica de 19 abril de 2005 significativamente titulada "Portugal pierde el miedo a España", pues la iniciaba con las siguientes palabras:
"El iberismo apenas se debate; ahora sencillamente se practica (...)" (Rusiñol, 2005). Los datos son elocuentes: España era en 2004 el primer cliente de Portugal al situar sus exportaciones entorno al $25 \%$ con 6.700 millones de euros; de forma análoga, en ese mismo año trescientas cincuenta empresas portuguesas estaban instaladas en España y sus inversiones doblaron a las españolas al alcanzar los 2.600 millones de euros frente a los 1.300. De entre todas habría que destacar la compra de Hidroeléctrica del Cantábrico por EDP, que se convertiría en el segundo operador de gas. La petrolera GALP, con cuarenta gasolineras en España, patrocinaría además la liga ACB de baloncesto.

La visibilidad de las empresas españolas en el cotidiano portugués modifica, sin duda, la percepción de la imagen de España en Portugal. La presencia de sondeos encargados por los medios de comunicación portugueses refleja en sí misma el impacto de esta visibilidad pero al proyectar una imagen mensurable permite calibrar su impresión valorada nuevamente desde la idea de la anexión. Así sucederá en septiembre de 2006, dos días antes de la llegada del presidente de la República Portuguesa, Aníbal Cavaco Silva, a España en visita oficial, prevista para el día 25. El iberismo vuelve a la actualidad. El nuevo semanario lisboeta Sol, dirigido por José António Saraiva, ex responsable de Expresso -que, recordemos, había publicado un sondeo parecido allá por 1986- publica una encuesta en la que el $27^{\prime} 7 \%$ de los portugueses se muestra a favor de que España y Portugal formen un único país: "São en número surpreendentemente elevado os portugueses que defendem um Estado ibérico único... e o regresso ao Império colonial", reza el subtítulo dado al reportaje aunque hay que advertir de que se trata, en realidad, de un porcentaje idéntico al mostrado veinte años atrás. Los encuestados entienden que el nuevo Estado debería ser una República (63'9\%), pero respecto a la capitalidad Madrid y Lisboa empatan en cuanto a las preferencias: $41^{\prime} 8 \%$ y 40 '7\%, respectivamente. La argumentación que justifica esta nueva organización política tiene que ver con causas internas: el 96'5\% cree que Portugal avanzaría en su desarrollo y sería tratado en condiciones de igualdad (68\%). Este último aspecto es particularmente revelador porque expresa la dimensión de su sentimiento nacional. Los portugueses no contemplan la desaparición de su nación, solo la del Estado, y la unión peninsular se concibe como una solución pragmática para superar problemas endógenos creando una estructura supranacional capaz de imponerse dentro del concierto europeo. El 56'4\% piensa que ha crecido el prestigio internacional de su país frente al 
$25^{\prime} 9 \%$ en que se cifraba veinte años antes pero, al mismo tiempo, el sondeo muestra un cierto desencanto ante Europa: casi la mitad, el 51'7\%, consideraba que Portugal había ganado con su entrada en la Unión Europea porcentaje que iguala a los que entendían que había perdido o se mostraban indiferentes (24'6\% y 20'9\%, respectivamente) (Sol, 2006, 22-23).

Las reacciones a la encuesta de Sol en Portugal no se hicieron esperar y oscilaron entre la serenidad con que António José Teixeira se expresaba en Diário de Notícias: "Não há conflitos indentitários, mas estamos longe de qualquer integração política" (Teixeira, 2006), a la clara alarma de Paulo Leitão en As Beiras que, en un durísimo artículo significativamente titulado en español "Los vendidos", tachaba de palurdos, traidores, babosos, faltos de espíritu nacional, simples y sin ambiciones personales y colectivas a quienes se manifestaban a favor de una hipotética Unión Ibérica. Para explicar este despropósito el autor culpaba a la clase política, responsable de la inexistencia de medidas sociales cifradas en las elevadas tasas de abandono escolar junto a una falta de preparación laboral de los trabajadores portugueses en una economía cada vez más modernizada. "A verdade é que não se consegue chegar a lado nenhum apenas colocando bandeiras vermelhas e verdes nas janelas quando a selecção de Portugal joga" (Leitão, 2006), finaliza. En medio de todo ello las palabras de Eduardo Lourenço al recoger en Badajoz el Premio Extremadura a la Creación que le había sido concedido vinieron a templar un poco un debate siempre susceptible de caer en extremismos:

\footnotetext{
"El iberismo debería ser nuestro estado natural, es nuestra realidad histórica de muchos siglos. La Península siempre fue una confrontación de diversidades que se han llevado bastante bien muchas veces. Las dificultades de convivencia solían venir del exterior. Ahora vivimos un iberismo práctico, sin connotaciones centralistas o imperialistas. Nadie quiere unirnos por la fuerza. Es admirable cómo España maneja dialogando las tentaciones de fuga separatistas, que por otro lado son irreales. Los portugueses, a nuestra manera suave, nos las arreglamos para imponer de forma natural nuestra autonomía, relativa como todas, a aquel viejo centralismo intolerable. Europa y el mundo tienen hoy tal ambición de uniformidad, que las tentativas de edificar castillos individuales ya no cuajan fácilmente" (Mora, 2006b).
}

En España la prensa acogió con nueva sorpresa los datos del sondeo (Mora, 2006c; Petschen, 2006; Bastenier, 2006). Preguntados, a su vez, los internautas en "Foro Digital" de El País sobre esta encuesta responden con escepticismo a la pregunta: “¿Podrían
Portugal y España forjar una alianza ibérica en el seno de la UE?" En general la percepción es que Europa proporciona esta estructura supranacional de resolución de conflictos que hace innecesaria cualquier otro tipo de unión (El País, 2006), algo que una encuesta española posterior realizada por la empresa Ipsos para la revista Tiempo al calor del debate periodístico desmiente aparentemente. Se realizó durante los días 6 a 8 de octubre con un muestreo de 588 entrevistas telefónicas en todo el ámbito peninsular más Baleares y Canarias, con un universo de individuos de entre 18 a 79 años de edad. Los datos arrojados son significativos: el $47^{\prime} 7 \%$ aprueba la unión, considera que el nuevo Estado debería llamarse España (43'4\%), que la capital debería ser Madrid $\left(80^{\prime} 0 \%\right)$ y la forma de dicho Estado la monarquía (49'7\%). Leyendo entre líneas los españoles de la encuesta de Tiempo parecen tan escépticos como los de "Foro Digital" y lo más destacable es la simpatía de las Comunidades Autónomas fronterizas: Galicia, Castilla-León, Extremadura y Andalucía, para las que la relación con Portugal forma parte de su tradición histórica, frente a las de la cuenca mediterránea o el País Vasco, donde se oponen (Tiempo, 2006, 40-42). El politólogo Andrés de Blas Guerrero interpreta el sondeo del semanario portugués como un triunfo de la sociedad española, capaz de culminar con éxito y eficacia su proceso de transición democrática, de conseguir un conjunto de reformas económicas y sociales que la han llevado a la situación actual, y de lograr una "densificación de sus relaciones culturales, sociales y vitales inigualable" en nuestra historia (De Blas Guerrero, 2006). Por su parte, la prensa portuguesa se apresuró a recoger los datos del nuevo sondeo con titulares diversos. Los lectores portugueses podían optar el mismo día por el aséptico y descriptivo: “Quase metade dos espanhóis é favorável a uma união entre Portugal e Espanha" de Público (Público, 2006), al claramente alarmista de Jornal de Notícias (Jornal de Notícias, 2006): “Espanhóis querem anexar Portugal", opinión diluida, sin embargo, en el texto al presentar de forma mucho más fría los datos de la encuesta española. Desde un punto de vista comparatista no deja ser significativo que los encuestados de uno y otro país tengan en mente su propia realidad política para definir las características del nuevo Estado unitario, lo que indica una idea fuertemente arraigada de su identidad político-nacional. Por eso, la visita de Aníbal Cavaco Silva a España, la primera como Presidente de la República portuguesa tras su toma de posesión, ofreció la oportunidad de efectuar un balance más ecuánime de las relaciones entre los dos países tras más de treinta años de demo- 
cracia. En sus distintos discursos Cavaco Silva subrayó la trascendencia de la integración en la Unión Europea para el desarrollo político y económico de España y de Portugal, y las positivas aportaciones de ambos en el estrechamiento de relaciones entre esta y América Latina, África y Asia, la pujanza de los intercambios comerciales y el impulso en el plano cultural. "Em síntese, conhecemo-nos hoje melhor, muito melhor. E trabalhamos em conjunto mais, muito mais do que no passado", afirmaba ante el pleno del Congreso de los Diputados (Silva, 2006).

Resulta evidente, sin embargo, que entre los sectores más conservadores la afirmación de "iberista" continúa siendo sinónimo de "antipatriota" y motivo de agrio debate, como ya notaran los viajeros españoles en sus visitas a Portugal a lo largo del siglo XIX (Peralta García, 2008, 177-195). Todavía en la primera década del siglo XXI el adjetivo mantiene sus negativas connotaciones decimonónicas entre un grupo de militares jubilados que denunciaron ante la Procuraduria Geral da República (Fiscalía General del Estado) al ministro de Obras Públicas por declararse en Santiago de Compostela un "iberista convencido". La realidad, por el contrario, se impone con datos abrumadores. Según la Câmara de Comércio e Indústria Luso-Espanhola (fundada en 1970) de Lisboa y del Instituto de Comércio Exterior (ICEP) en 2007 mil cincuenta empresas españolas estaban instaladas en Portugal y cuatrocientas portuguesas operaban en España con sedes dispersas por casi todas las comunidades autónomas ${ }^{24}$, siendo muchas de ellas pequeñas y medianas empresas (Mora, 2007a). Algunas, como Sacyr y Chamartín, incluso con accionariado en los equipos de fútbol pues tras la compra de Somaque y Amorim Imobiliária se convertirían en propietarias del $18 \%$ del Porto Clube de Futebol. En el sector textil Cortefiel fue quizá la primera empresa en instalarse en Portugal en 1991 y a ella se unirían el grupo Inditex en 1998 y posteriormente El Corte Inglés cuando decidió salir fuera de España tras dos años de estudios minuciosos. Lisboa (2002) y Vila Nova de Gaia (2004) fueron los lugares de emplazamiento elegidos (Expansión, 2004). En 2003 un acuerdo entre el Banco Popular y el Banco Nacional de Crédito Imobiliário (BNC) permitió al primero entrar en el mercado portugués al adquirir el $75 \%$ de esta entidad financiera y al empresario Américo Amorim, en virtud del acuerdo alcanzado, sentarse en el Consejo de Administración del banco español (El Mundo, 2003) ${ }^{25}$. El Banco Internacional de Funchal (BANIF) entraba en 2007 en el sector bancario español con la compra de participaciones en Banco Pueyo y en Bankpime. Además, el Banco Comercial Português posee el 4'6\% de Banco Sabadell.
En el ámbito de la salud la creación de las euroregiones ha permitido al Hospital Materno-Infantil de Badajoz ofrecer programas de atención para mujeres portuguesas embarazadas a lo largo de todo el proceso y atender a enfermos de diversas especialidades y está previsto resolver problemas concretos como el traslado de cadáveres, la homologación del calendario de vacunas, la coordinación de las alertas sanitarias o la creación de un banco de órganos. El sector de la cultura y el turismo están plenamente consolidados y se ha avanzado mucho en el terreno de la cooperación policial: explotación sexual, terrorismo, lucha contra el tráfico de drogas... (Mora, 2006a) y en programas conjuntos, como el de la extinción de incendios a ambos lados de la frontera en las regiones del Norte de Portugal y Castilla-León (Junta de Castilla y León, 2003, enero-junio). Además, España y Portugal impulsan de mutuo acuerdo el Laboratorio Ibérico de Nanotecnología ${ }^{26}$, una colaboración que el ministro portugués de Ciencia, Tecnología y Educación Superior pretendía extender para la creación de grados universitarios conjuntos en el ámbito peninsular que se impartirían en los dos países (Álvarez, 2011). Por todo ello, las declaraciones de Saramago en 2007 en una entrevista a Diário de Notícias a propósito de la publicación de $O$ Evangelho segundo Jesus Cristo reafirmando su iberismo inequívoco al vaticinar la integración de España y Portugal en un espacio común llamado Iberia, volverían a sembrar la polémica:

“(...) Integrados o que é que aconteceria? Não deixaríamos de escrever em português, não deixaríamos de escrever na nossa língua e certamente com dez milhões de habitantes teríamos tudo a ganhar em desenvolvimento nesse tipo de aproximação e de integração territorial, administrativa e estrutural. (...) Seríamos aqui aquilo que os catalães querem ser e estão a ser na Catalunha" (Diário de Notícias, 2007; también Mora, 2007c, 2007b; El País, 2007; Yáñez, 2007)27.

No se trataba de una manifestación desconocida. Como hemos comentado antes el, hasta la fecha, único Premio Nobel portugués ya se había expresado en estos términos, quizá por primera vez, con la publicación en 1986 de A Jangada de Pedra y a partir de aquí lo reiteraría en multitud de reuniones y encuentros, no solo literarios (Conte, 1986; El País, 1989; Saramago, 1990, 5-9; El País, 1995a; García Posada, 1998; Egea, 2010; Martín Ferrand, 2010, 14). En la Feria del Libro de Guadalajara (México), a la que había asistido unos meses antes, afirmaría: "Soy un andaluz por adopción porque la provincia de Granada me nombró hijo adoptivo. Hasta el final de mi 
vida no tengo más remedio que ser hijo adoptivo de la provincia de Granada. (...) En primer lugar, soy portugués; luego, soy ibérico; y, finalmente, europeo. Por circunstancias de mi vida, de mi trabajo y de orden sentimental, me he hecho más ibérico de lo que yo creía que alguna vez llegara a ser" (Belausteguigoitia, 2006). Por si faltase algo su narrativa, como señala el profesor Fernando Venâncio, está llena de españolismos (Venâncio, 2006).

Tampoco es el único autor que se ha pronunciado en este sentido. Antes que él, y en un pasado relativamente reciente, habían abordado el tema del iberismo Natalia Correia en la antología Cantares de trovadores galaico-portugueses (1970) y abiertamente en Todos somos hispanos (1986), y Miguel Torga en Poemas ibéricos, publicado en España en Ediciones Cultura Hispánica (1984). En esta ocasión Saramago era recordado, en sus propuestas federalistas, en una entrevista a Günter Grass por la revista portuguesa Visão ${ }^{28}$. Y quizá fuese eso, que las opiniones del novelista portugués cobrasen carta de naturaleza en la voz de Grass, un escritor perteneciente a un espacio geográfico y cultural tan alejado del ibérico pero integrado bajo una estructura política de Estados federales que constituyen una única nación, lo que indignó y exacerbó la polémica.

En 2009 se publica el Barómetro de Opinión Hispano-Luso (BHOL) (Fernández Enguita, Santiuste Cué, y Hernández Bejarano, 2009) dirigido por el Centro de Análisis Sociales de la Universidad de Salamanca, el único estudio con carácter oficial sobre las relaciones hispano-portuguesas. En él se documenta cómo la mayoría de los encuestados opina que las relaciones entre ambos países son buenas o muy buenas $\left(60{ }^{\prime} 8 \%\right.$ entre los españoles, y 55'1\% entre los portugueses), y cuando son preguntados sobre problemas comunes los ciudadanos de ambos Estados manifiestan una clara disparidad de opiniones que indica que las preocupaciones a ambos lados de la raya son bastante más prosaicas, más concretas y responden a problemas a los que la población es especialmente sensible. En Portugal se trata del aprovechamiento de los ríos (25'3\%) mientras que en España es el uso del territorio como refugio de terroristas (51'3\%). En ambos casos los datos encierran desasosiegos un tanto ficticios: en el caso portugués el porcentaje es solo relativamente significativo, mientras que del lado español hay que señalar que únicamente en casos muy recientes y residuales, ante la presión policial y la estrategia conjunta con Francia, Portugal merecería la atención del terrorismo de ETA. Es también significativo que ni la delimi- tación de fronteras, ni las inversiones empresariales, ni las comunicaciones por carretera y ferrocarril sean motivo de preocupación y, por el contrario, proyectos de cooperación conjunta en materia policial, judicial y militar, o la supresión de las restricciones de movilidad y asentamiento de profesionales, trabajadores y empresas cuentan con el respaldo mayoritario de los ciudadanos. Saramago se sintió arropado (Saramago, 2009), mientras la prensa española subrayaba las simpatías portuguesas hacia una eventual unificación política (Peinado, 2009).

Ante esta evolución de las relaciones hispanoportuguesas a lo largo de los años resultaría muy revelador de la utilización del iberismo como arma de desprestigio político en pleno siglo XXI un episodio protagonizado por la candidata del Partido SocialDemocrata, Manuela Ferreira Leite, a las elecciones legislativas de 27 de septiembre de 2009. El día 13, en un debate televisado con el candidato socialista, José Sócrates, avanzó la intención, si llegaba a presidir el gobierno, de paralizar algunos proyectos de desarrollo conjunto con España, especialmente la línea del tren de alta velocidad, con el argumento de que "Portugal não é uma província de Espanha", y que dicha obra favorecía fundamentalmente los intereses españoles. Como no podía ser de otra manera la prensa se haría eco de sus declaraciones. Los nuevos datos económicos aportados por la Câmara de Comércio e Indústria Luso-Espanhola hablan ahora de 1.200 empresas españolas asentadas en Portugal, el $50 \%$ de la inversión extranjera (22.000 millones de euros) que proporcionan 80.000 empleos entre las familias portuguesas; en España hay que hablar de 400 empresas portuguesas y una inversión de 11.000 millones de euros que dan empleo a 22.000 familias españolas (Relea, 2009). Luís Filipe de Menezes Lopes, también miembro del PSD, publicaba en esos días en el periódico El País su análisis de la polémica con la mirada puesta en las posibilidades del mercado ibérico en su conjunto, 52 millones de consumidores potenciales. Según Lopes, para lograrlo habría que avanzar en la modernización de los puertos de la costa atlántica, en sus enlaces por ferrocarril y carretera, en la armonización fiscal y la paulatina introducción del español y el portugués en la enseñanza obligatoria (Lopes, 2009), una actitud en sintonía con las reacciones de decepción que en 2005 suscitó entre algunos líderes del PSD o del presidente de la Câmara Oficial de Comércio e Indústria do Porto, Rui Moreira, la decisión del gobierno de José Sócrates de retrasar sine die la entrada en funcionamiento de la línea Aveiro-Salamanca en detrimento de la construcción del nuevo aeropuerto de Alcochete, cercano 
a Lisboa (Junta de Castilla y León, 2005, julio-diciembre, 355-357, 401, 408 y 413). El gobierno español, en la persona del ministro de Fomento, José Blanco, también saldría al paso de las declaraciones de Manuela Ferreira Leite restando importancia al episodio (Económico, 2009). Paradójicamente, las reacciones suscitadas en España provocarían el enfado del politólogo José Adelino Maltez que acusó a la prensa española de "provincianismo" (www.tsf.pt). Sin embargo, tras la convocatoria anticipada de elecciones legislativas en junio de 2011, después de la negativa de la Assembleia da República a aceptar el plan de ajuste de José Sócrates y la constitución de un gobierno conservador de coalición (PSD-PP-CDS), la cuestión del AVE sería nuevamente planteada. En el Programa do XIX Governo Constitucional propuesto por la Presidência do Conselho de Ministros se prevé "suspender o projecto de "Alta Velocidade» Lisboa-Madrid", en lo que parece ser una concesión a los sectores oposicionistas al proyecto. No obstante y a pesar de lo taxativo de su redacción se afirma que "poderá sujeitar-se o projecto a uma reavaliação, incluindo o seu conteúdo e calendário, numa óptica de optimização de custos, à luz dos novos condicionalismos, e que deverá ter em conta o estatuto jurídico dos contratos já firmados. Uma eventual renegociação só poderá proceder de uma avaliação deste tipo" (Presidência do Conselho de Ministros, 2011, 41; El País, 2011b). En este sentido el Primer Ministro Passos Coelho, de visita en España unos meses más tarde, matizaría los términos de la suspensión restringiéndolos solo al transporte de viajeros frente al de mercancías por la necesidad de contar con "un corredor central en ancho europeo que ligue, desde los puertos de Sines y Algeciras, la península con el resto de Europa. Para el crecimiento económico, esto es más prioritario que el transporte de viajeros" (Relea, 2011). El proyecto se abandonaría definitivamente a principios de 2012.

La crisis financiera global de 2008 haría más visibles todavía los vínculos de las economías de España y Portugal. La banca española, por ejemplo, concentraba en 2011 aproximadamente el 7\% del PIB español en activos financieros portugueses, un $34 \%$ del total de la banca internacional ${ }^{29}$. De ahí que las dificultades de Portugal, atrapado en un estancamiento prolongado y falto de reformas, lo llevaran finalmente a solicitar una ayuda financiera a Bruselas cifrada en 78.000 millones de euros, a pesar de los desesperados esfuerzos de su primer ministro, José Sócrates, por evitarlo reclamando una y otra vez la puesta en marcha de los eurobonos. Un testigo de excepción, el presidente español José Luís Rodríguez Zapatero, que lo apoyó en su ini- ciativa, alude en El dilema a la profunda decepción de este hacia Bruselas una vez consumado el rescate (Rodríguez Zapatero, 2013: 282-283). Este apoyo fue inicialmente descartado para España tras la aprobación de un conjunto de medidas de recorte del gasto público tras la sesión en el Congreso de los Diputados de 12 de mayo e implementadas a partir de esta fecha y a lo largo de 2011 (Rodríguez Zapatero, 2013: 13 y ss.), pero también con la convicción de que el volumen de España es lo suficientemente grande como para que un ataque sobre la deuda española podría llevar a una crisis sobre la estabilidad y viabilidad del euro. En nota difundida por Barclays Capital se aseguraba que: "los vínculos entre la economía española y la portuguesa obligan a pensar que las perspectivas para España no son independientes de lo que suceda en Portugal. Aún así, los mercados continuarán diferenciando entre pequeños y grandes países: no es previsible un contagio como en las primeras etapas de la crisis" (Pérez, 2011). Tras el anuncio del gobierno interino portugués de la aceptación de la ayuda financiera ni los indicadores económicos ni la bolsa española se vieron afectados aunque durante el segundo semestre de 2011 la recesión se agudiza. En España, a pesar de los resultados positivos de su evolución macroeconómica, la necesidad de reestructuración y recapitalización de su sistema financiero llevaron a la solicitud de apoyo (8 de julio de 2012) ante las instituciones europeas al amparo de la aprobación, el día 21 de julio de 2011, de un Mecanismo Europeo de Estabilidad (MEDE). La cuantía se fijó en torno a los 60.000 millones de euros (primer trimestre de 2012), que debe ser gestionado por el nuevo gobierno de Mariano Rajoy.

\section{CONCLUSIONES}

La idea de la unión o anexión política de los dos países que conforman mayoritariamente la península Ibérica supone la recepción aquí de las teorías nacionalistas que a finales del siglo XIX Ilevaron a la unificación de Italia y Alemania. Desde entonces las relaciones entre España y Portugal han pasado por multitud de fases y períodos históricos que han oscilado habitualmente entre la tensión y la colaboración. En el último cuartel del siglo $\mathrm{XX}$, con la recuperación de la democracia en ambos países, el iberismo ha reflejado esta nueva situación actualizando e intensificando la relación política que se ha acompañado de un fortalecimiento de los intercambios económicos y sociales. Quizá el sector de más lento desarrollo haya sido el de la cultura. Como señala Maria de Fátima Amarante el éxito de la cooperación hispano-portuguesa conoce asimetrías desde el punto de vista interregional -más 
estrecho entre Galicia y la Região Norte de Portugal, Extremadura y Alentejo, Andalucía y Algarve, y menos desarrollado en el eje Castilla-León y las Beiras Interiores- pero también a nivel institucional -con la creación de la Fundación Rei Afonso Henriques (Zamora, 1994) y el Centro de Estudos Ibéricos (Guarda, 2000), o los acuerdos entre entidades locales: la Diputación de Badajoz y la Associação de Municípios do Norte Alentejano (INTERREG III 2000-2006), y entre los ayuntamientos de Salamanca y Guarda (2007)- y en el intercambio de personas, más fluido en el ámbito de la Educación Superior y en los encuentros de profesionales de alta cualificación (Amarante, 2009, 160-161). Un comentario especial merece la acción de la Fundación Príncipe de Asturias y los premios internacionales a ella asociados que aun con un pequeño déficit a la hora de distinguir a profesionales portugueses sí lo ha hecho, en repetidas ocasiones con brasileños ${ }^{30}$, a lo largo de sus más de veinticinco años de existencia. En este sentido habría que destacar los galardones a Mário Soares (Cooperación Internacional, 1995), Joaquim Veríssimo Serrão (junto a Miguel Batllori i Munné, Ciencias Sociales, 1995) y António Damásio (Investigación Científica y Técnica, 2005). Sin embargo y a pesar del esfuerzo realizado tanto desde las instituciones públicas como desde las empresas privadas la percepción de las relaciones entre España y Portugal sigue estando presidida por la repetición incansable de tópicos. Al margen de los datos facilitados por el BHOL cabe preguntarse hasta qué punto estas imáge- nes, coincidentes o antinómicas, de españoles y portugueses a respecto del otro responden en realidad a los intereses y las preocupaciones de los ciudadanos o si son, en realidad, una construcción elitista. Ya Raúl Morodo, en aquel lejano 1983, se formulaba la misma pregunta (Morodo, 1983a) y percibía un cierto cambio de actitud en el $26 \%$ de portugueses que en aquellos años abogaban por una unidad política con España. Según el BHOL en 2009 el porcentaje se eleva al $39^{\prime} 9 \%$, mientras que entre los españoles alcanza el $30^{\prime} 3 \%$, cifras que parecen desmentir la idea de la confrontación atávica de la enemistad y rivalidad de sus relaciones. A tenor de lo expuesto a lo largo de este artículo lo que sí parece resistir es una cierta idea de desconocimiento del otro aunque en la mayoría de los casos parece expresar más bien una simple percepción subjetiva de la realidad de individuos en concreto, pues el volumen creciente de los intercambios políticos, económicos, sociales y culturales denuncia una situación muy diferente en términos objetivos. Además, tanto la manifestación del desdén español como la utilización del iberismo como arma de confrontación política en aras de la defensa de la identidad portuguesa no solo no parecen tener cabida en el nuevo orden global sino que su oposición por parte de las administraciones públicas, las empresas privadas y los sectores de mayor cualificación socioprofesional evidencian la superación de viejos y caducos tópicos en las relaciones hispano-portuguesas o luso-españolas a pesar de los persistentes choques culturales.
1 La historiografía considera de forma unánime que con el primer gobierno socialista (1982-1986) se cierra el proceso de transición política y se consolida la democracia en España. Vid. por ejemplo (Tusell, 1999, 265-266; Díaz Gijón, 2001, 298; Marín, José María, Molinero, Carme, e Ysàs, Pere, 2001).

2 Una síntesis sobre la definición de los conceptos "Iberia" e "Iberismo" en (Peralta García, 2000, 391-395).

3 Sobre la postura de Francia en el proceso de negociación vid. (Lemus, y Pereira Castañares, 2003, 522-529).
4 Siendo rector D. Julio Fermoso García y a propuesta del Departamento de Derecho Público y de la Facultad de Derecho, asumida por la Junta de Gobierno (23 de noviembre de 1987). La defensa corrió a cargo de su decano, el Dr. D. Manuel C. Palomeque López, que destacó "las razones intelectuales y profesionales que concurren en D. Mario Soares y que avalan la concesión por la Universidad de Salamanca del Doctorado «honoris causa»"; subrayó la importancia de "su obra intelectual, materializada en sus publicaciones y su actividad como Profesor en las Universidades Europeas; su inestimable contribución a la institucionalización del Estado democrático portugués, su prestigio internacional como estadista y publicista". El profesor Palomeque López finalizó su defensa resaltando "la posición de España en sus relaciones con Portugal y la especial situación de la Universidad de Salamanca en la articulación intelectual y universitaria de estas relaciones". La propuesta fue sometida a votación de los Claustrales Doctores por el sistema de bolas blancas (52) y bolas negras (29), el día 26 de noviembre de 1987 (Universidad de Salamanca, 1987).

5 Sobre la presencia de la literatura portuguesa en España en los siglos XIX y XX vid. (Molina, 1990). 
6 Crítica en (ABC Literario, 1987, III). En portugués la novela se había publicado un año antes (Saramago, 1986).

7 (Saramago, 1987a; crítica en ABC Literario, 1990, III). (Saramago, 1996; crítica de Conte, 1996, 13) (Antunes, 2000; crítica de Solano, 2000, 13; crítica de Machover, 2001). (Queirós, 2001; crítica de Guelbenzu, 2001). (Saramago, 2001; crítica de García Galiano, 2001). (Jorge, 2002).

8 Por ejemplo: (Castelo Branco, 1989). (Queirós, 2003; referencia a su obra y alusiones al iberismo en Rodríguez Rivero, 2004, 3). (Pessoa, 2004). (Pascoaes, 2000; referencia a la obra del autor en De Villena, 2007).

9 De la encuesta de Expresso se hacía también eco Raúl Morodo (Morodo, 1983a).

$10 \mathrm{El}$ gesto fue comentado en $A B C$ con las siguientes palabras: "Los hombres de Estado -no los politiquillos de regate corto y mirada restringida- actúan así: sobreponiéndose a las contingencias personales, sirviendo por encima de todo al puesto en que su comunidad los ha situado. El ejemplo de Soares, político moderado, prudente y equilibrado, es doble: hace honor al pueblo que lo eligió y, al mismo tiempo, subrayaba la trascendencia de las relaciones entre dos países a los cuales todo obliga al entendimiento" (ABC, 1989c, 31).

11 En la "Nota" de presentación al volumen José Bento escribe: "Que Por tierras de Portugal y de España tenha tido de esperar setenta e oito anos para ser traduzido e publicado em Portugal dá medida do afastamento que se tem verificado entre Portugal e Espanha. Se as relações culturais luso-espanholas tivessem a dimensão imposta pela proximidade geográfica, a história política e cultural com significativos pontos comuns e o interesse num profundo conhecimento recíproco, há muito que este livro, em que a alma de Portugal é olhada com paixão, circularia entre nós e na nossa língua como obra indispensável para se conhecer não só a nação que éramos quando ele foi escrito como o que somos hoje". (Unamuno, 1989, VII).

12 Hasta 1982 la presencia de Portugal en la prensa española es poco significativa y reducida a noticias de carácter cultural. A propósito de un artículo sobre el músico Fernando Lopes Graça escribe el corresponsal de El País: "Desde su postura ética y polémica entendió Lo- pes Graça que se hacía preciso conectar directamente con el pueblo, y para él escribió gran número de coros, marchas y canciones de fácil asimilación (...). El iberismo, en el que cree profundamente el compositor, salvó de posibles convencionalismos las Canciones sobre versos de García Lorca, de 1954". Vid. (Franco, 1981); también (E. F., 1981): “De ese estilo vocal parece derivarse el tratamiento orquestal, uno y otro sumergidos en un difuminado iberismo que, con frecuencia, se concreta en el lánguido ritmo de una habanera".

13 Aunque sea con motivo de su fallecimiento (El País, 1993; Moreira, 1993).

14 Una visión del iberismo de Torga presentado desde una perspectiva ajena al mundo luso-español es posible en (Armbruster, 2008, 235-253).

15 Los titulares de $A B C$ y El País son coincidentes: "Fallece a los ochenta y siete años Miguel Torga, el patriarca de la poesía portuguesa. Portugal llora la desaparición de un símbolo de la resistencia" ( $A B C, 1995,47-50)$. "Muere a los 87 años Miguel Torga, patriarca de la literatura portuguesa contemporánea. Sucesor de Camoens y Pessoa, su obra fue traducida a veinte idiomas" (El País, 1995).

16 ( $A B C, 1995 b, 48-50)$. Unos días después de su muerte la Universidade Nova de Lisboa le rindió un homenaje al que estaba invitado Camilo José Cela que delegó su presencia en la del periodista de $A B C$ José María Moreiro (S. C., 1995 48). También Torrente Ballester expresó su reconocimiento al autor en un congreso celebrado en Trás-os-Montes para analizar su obra $(A B C, 1994 \mathrm{~b}, 65)$.

17 Con motivo de la apertura de la Expo '98 $A B C$ publicaba un artículo de Duarte de Braganza, pretendiente al trono de Portugal y heredero de los derechos dinásticos, sobre la pujanza de la lengua portuguesa a lo largo de los siglos y en la actualidad. Con una percepción un tanto desenfocada debido a algunas afirmaciones que, aunque con adeptos en España, resultan polémicas en Portugal y también en el ámbito científico, el autor esperaba que con la difusión del portugués se comprendiese mejor a Portugal: "Cerca del paso al tercer milenio, tampoco puede dejar de constituir un motivo de alegría para un portugués comprobar que España, tras algunas décadas de paréntesis, parece haber retomado plenamente conciencia de la importancia de la lengua gallega, ma- dre de la lengua portuguesa. En efecto, el portugués es el idioma gallego, que evolucionó en contacto con el mundo. Pero si no fuese debido a una extraña ortografía que fue adoptada modernamente en Galicia, no existiría ninguna dificultad para la comprensión mutua. Entre tantas ventajas que presenta ese desarrollo, no puedo dejar de apuntar una que me parece esencial y en la que deposito una sincera esperanza: el que, al ser el portugués considerado por los españoles como una de las lenguas habladas en su país, puedan comprender mejor a Portugal". (Braganza, 1998, 38).

18 Como el congreso internacional Los 98 Ibéricos y el Mar o el dedicado a la Transición Española, ambos celebrados en Lisboa. Vid. los volúmenes de actas (AA. VV., 1998; AA.VV, 2000).

19 Se trata de un debate también un tanto persistente (Trías de Bes, 1995, 24; Seco Serrano, 1998; Ayala, 1998, en respuesta al artículo de Carlos Seco; Rubert de Ventós, 1999). Sobre las similitudes de Cataluña y Portugal vid. (Martínez, 1999; Mascarell, 2007). Una síntesis sobre las teorías iberistas en Cataluña es posible en (Martínez i Gil, 1996).

20 Algunos meses antes una reunión de escritores, intelectuales, poetas, críticos y editores abogaban en Extremadura por la normalización de las relaciones culturales entre España y Portugal. (Clemente, 1998).

21 Sobre las relaciones Portugal-España a través del futbol remitimos al artículo del profesor Francisco Pinheiro, en este mismo dossier.

22 A raíz de una queja realizada en mayo de 2002 por cuarenta empresarios portugueses en una carta enviada al primer ministro, José Manuel Durão Barroso, y al presidente de la República, Jorge Sampaio. No se mencionaba a España pero se solicitaba frenar la entrada de capital extranjero y mantener los centros de decisión en Portugal. Vid. (M. P., 2003; Sampaio, 2003; $A B C, 2003,35)$.

23 El trazado de la línea de Alta Velocidad suscitaría un apasionado debate en la provincia de Salamanca como ya lo había hecho más de un siglo antes la construcción del primer ferrocarril. Vid., por ejemplo, su reflejo en los periódicos de la región en (Junta de Castilla y León, 2003). A partir de 2005 las dificultades del déficit público portugués obligarán a una revisión del calendario de implantación. Los corredores Madrid-Lisboa 
y Vigo-Oporto se retrasaron a 2013 y 2014, respectivamente, y las conexiones Salamanca-Aveiro y Sevilla-Faro dejaron de ser prioritarias. Vid. (Junta de Castilla y León, 2005, julio-diciembre, $61,65,90,277,305,308,338,340,341$, $346-352,418$ y 421$)$.

24 Los datos son los siguientes: 134 en Madrid, 60 en Galicia, 41 en Cataluña, 15 en Andalucía, 13 en Castilla y León, 10 en Valencia, 6 en Extremadura, 5 en el País Vasco y Castilla-La Mancha, 4 en Navarra, 2 en La Rioja y Murcia (Mora, 2007a).

25 Américo Amorim es uno de los principales accionistas del Banco Popular con el control del 6'92\% del accionariado.

26 Inaugurado en Braga el 17 de julio de 2007.
27 Un punto de vista más tópico, recogiendo esta polémica, es el expresado por (Gibson, 2007).

28 Grass respondía a una pregunta sobre sus relaciones con Saramago. Su respuesta íntegra fue la siguiente: "Gosto dos seus livros. Encontrei-o algumas vezes... É mais velho do que eu e ainda está aí para as curvas. Recentemente veio a público com uma proposta interessante: a criação de um Estado ibérico, que integrasse Portugal e a Espanha numa ordem federalista. Talvez não seja realizável, mas devia pensar-se nisso. Um Estado ibérico teria, na Europa, num contexto federal, um peso muito maior do que dois Estados isolados" (Galope, 2007).
29 Banco Santander: 3.632 millones de euros; BBVA: 647 y Banco Popular: 643, según datos de la Autoridad Bancaria Europea (El País, 2011a).

30 Grupo de Comunicación O Globo (Comunicación y Humanidades, 1986); Óscar Niemeyer (Artes, 1989); Movimento Nacional de Meninos e Meninas da Rua (junto a Save the Children, Concordia, 1994); Sebastião Salgado (Artes, 1998); Fernando Henrique Cardoso (Cooperación Internacional, 2000); Selección Brasileña de Fútbol (Deportes, 2002); Luiz Inácio Lula da Silva (Cooperación Internacional, 2003); y Nélida Piñón (Letras, 2005). Las actas de los jurados están disponibles en la página web de la Fundación. Vid. el enlace: http://www.fpa.es/es/cargarAplicacionPremiadoCompleto.do.

\section{BIBLIOGRAFÍA}

AA.VV. (1998): Los 98 Ibéricos y el Mar, 5 tomos, Madrid, Comisaría General de España, Expo Lisboa'98.

AA.VV. (2000): A Transição Democrática em Espanha, 2 vols., Lisboa, Fundação Mário Soares y BBVA.

ABC (1988): "Ayuda efectiva a Portugal", Madrid, 27 de agosto.

ABC (1989a): "La fecundidad portuguesa, según los autores españoles", Madrid, 8 de junio.

ABC (1989b): "Literatura portuguesa", Madrid, 6 de junio.

$A B C$ (1989c): "Soares, estadista ejemplar", Madrid, 18 de mayo.

$A B C$ (1989d): "Un nuevo iberismo", Madrid, 18 de mayo.

$A B C$ (1989e): "Unamuno", Madrid, 21 de diciembre.

$A B C$ (1990a): “Cavaco: la atención de la CE al Este no debe perjudicar a la Península", Madrid, 1 de febrero.

$A B C$ (1990b): "Cumbre hispano-portuguesa", Madrid, 3 de febrero.

$A B C$ (1990c): "Soares: "Sin Castedo y sin Galdós es incomprensible la novela del siglo XIX»", Madrid, 6 de mayo.
ABC (1994a): "España y Portugal”, Madrid, 9 de mayo.

ABC (1994b): "Torrente Ballester: «He seguido a Torga con atención amorosa y admiración confesa»", Madrid, 6 de marzo.

$A B C$ (1995): "Fallece a los ochenta y siete años Miguel Torga, el patriarca de la poesía portuguesa. Portugal Ilora la desaparición de un símbolo de la resistencia", Madrid, 18 de enero.

ABC (2001): “Icíar Bollaín protagoniza "La balsa de piedra», basada en la obra de Saramago", Madrid, 16 de abril.

$A B C$ (2003): Madrid, 9 de noviembre.

ABC Literario (1987): Madrid, 3 de octubre. ABC Literario (1990): Madrid, 7 de abril.

Acuña, Ramón Luis (1992): “Entrevista a Dinis Abreu, director de "Diario de Noticias»", $A B C$, Madrid, 27 de febrero.

Alvarez, Eloísa (1996): "Iberismo, hispanismo e hispanofilia en Portugal en la última década", Revista de História das Ideias, 18, Coimbra, Universidade de Coimbra.

Álvarez, Pilar (2011): “Entrevista: Mariano Gago. Ministro portugués de Ciencia y Educación Superior", El País, Madrid, 30 de mayo.
Amante, Maria de Fátima (2009): "Cultura e Cooperação: desafos e entraves à relação ibérica no contexto europeu", Revista População e Sociedade. Relações Portugal-Espanha. Partilha $e$ Fronteira, no 17, Porto, CEPESE - Centro de Estudos da População, Economia e Sociedade / Edições Afrontamento, pp. 155-168.

Antunes António Lobo (2000): Exhortación a los cocodrilos, Madrid, Siruela.

Antunes, José Freire (2003): Os Espanhóis e Portugal, Lisboa, Oficina do Livro.

Armbruster, Claudius (2008): “Espanha e Portugal en Miguel Torga", en Brandenberger, Tobias, Hasse, Elisabeth y Schumuck, Lydia (Eds.), A Construção do Outro: Espanha e Portugal frente a frente, Tübingen, Calepinus Verlag.

Ayala, Francisco (1998): "Reflexiones Vanas", El País, Madrid, 13 de marzo.

Bastenier, M. Á. (2006): “Esp-ugal o Portupaña", El País, Madrid, 4 de octubre.

Belausteguigoitia, Santiago (2006): "Saramago y Castilla del Pino hablan sobre la historia de Andalucía", El País, Madrid, 27 de noviembre.

Blanco Tobío, Manuel (1983): “Una cumbre para octubre", $A B C$, Madrid, 25 de julio. 
Blanco, María Luisa (2000): "Los hombres no aman: se aman a sí mismos a través de las mujeres", ABC Cultural, Madrid, 29 de abril.

Braganza, Duarte de (1998): “La lengua portuguesa como lengua mundial", $A B C$, Madrid, 17 de marzo.

Campelo, Sara (2005): “Televisión Española traza la historia hispano-lusa con «La raya quebrada»", $A B C$, Madrid, 11 de abril.

Cardoso, Miguel Esteves (1990): A Causa das Coisas, Lisboa, Assírio \& Alvim, 10ae ed.

Castelo Branco, Camilo (1989): Amor de Perdición, Barcelona, Planeta.

Clemente, Jeremías (1998): “Las literaturas de Portugal y España se acercan en Trujillo", El País, Madrid, 21 de junio.

Conte, Rafael (1986): “Imágenes de Saramago", El País, Madrid, 16 de diciembre.

Conte, Rafael (1996): ABC Literario, Madrid.

Conte, Rafael (1998): "Saramago, primer Nobel de las Letras Portuguesas. Un gran escritor comprometido", $A B C$, Madrid, 9 de octubre.

Cortes (1982): Diario de sesiones del Congreso de los Diputados, no 3, II Legislatura, sesión plenaria no 3, 30 de noviembre. Texto íntegro: http://www. la-moncloa.es/Presidente/Presidentes/ InvestiduraGonzalez1982.htm

Cortes Generales (1986): Diario de sesiones del Congreso de los Diputados. Pleno y diputación permanente, $\mathrm{n}$ - 2, III Legislatura, sesión plenaria no 2, 22 de julio. Texto íntegro: http://www.la-moncloa. es/Presidente/Presidentes/InvestiduraGonzalez1986.htm

Cortes Generales (1989): Diario de sesiones del Congreso de los Diputados. Pleno y diputación permanente, $\mathrm{n}$ ㅇ 2, IV Legislatura, sesión plenaria nㅇ 2, 4 de diciembre. Texto íntegro: http://www. la-moncloa.es/Presidente/Presidentes/ InvestiduraGonzalez1989.htm

Cortes Generales (1996): Diario de sesiones del Congreso de los Diputados. Pleno y diputación permanente, $\mathrm{n}$ ㅇ 2, VI Legislatura, sesión plenaria $\mathrm{n}$ ㅇ 2, 3 de mayo de 1996. Texto íntegro: http://www. congreso.es/portal/page/portal/Congreso/PopUpCGI?CMD=VERLST\&BASE =puw6\&FMT=PUWTXDTS.fmt\&DOCS $=11 \& Q U E R Y=\% 28 C D P 199605030002$. CODI.\%29\#(Página25)

Cortes Generales (2000): Diario de sesiones del Congreso de los Diputados. Pleno y diputación permanente, $\mathrm{n}$ ㅇ 2 , VII Legislatura, sesión plenaria no 2 ,
25 de abril. Texto íntegro: http://www. congreso.es/portal/page/portal/Congreso/PopUpCGI?CMD=VERLST\&BASE =puW7\&FMT=PUWTXDTS.fmt\&DOCS $=11 \&$ QUERY $=\% 28 C D P 200004250002$. CODI.\%29\#(Página22)

Cortes Generales (2004): Diario de sesiones del Congreso de los Diputados. Pleno y diputación permanente, $\mathrm{n}$ ㅇ 2, VIII Legislatura, sesión plenaria $\mathrm{n}$ ㅇ 2, 15 de abril de 2004. Texto íntegro: http://www. la-moncloa.es/Presidente/Presidentes/ InvestiduraZapatero2004.htm

Cortes Generales (2008): Diario de sesiones del Congreso de los Diputados. Pleno y diputación permanente, $\mathrm{n}$ 은, IX Legislatura, sesión plenaria $n=2,8$ de abril de 2008. Texto íntegro: http://www. la-moncloa.es/Presidente/Presidentes/ InvestiduraZapatero2008

Crespo, Ángel (1985a): “El iberismo de Fernando Pessoa", El País, Madrid, 6 de julio.

Crespo, Ángel (1985b): "España y Portugal según Pessoa", El País, Madrid, 22 de mayo.

Crespo, Ángel (1987): "El iberismo de Fernando Pessoa", El País, Madrid, 21 de diciembre.

De Blas Guerrero, Andrés (2006): “Noticias de Portugal”, El País, Madrid, 24 de octubre.

De Diego, Estrella (2011): "Una poesía radical de arte y víscera", El País, Madrid, 11 de mayo.

De León-Sotelo, Trinidad (1998): "Saramago, a corazón abierto", $A B C$, Madrid, 10 de octubre.

De Villena, Luis Antonio (2007): “Añoranza en luz de luna", El País, Madrid, 20 de enero.

Diário de Notícias (2007): “Não sou profeta, mas Portugal acabará por integrar-se na Espanha", Lisboa, 15 de Julho.

Díaz Gijón, José Ramón (2001): “Época socialista (1982-1996)", en AA.VV, Historia de la España actual: 1939-2000. Autoritarismo y democracia, Madrid-Barcelona, Marcial Pons, ediciones Jurídicas y Sociales, 2a ed.

E. F. (1981): "El teatro musical de Falla y Ravel", El País, Madrid, 24 de noviembre.

Económico (2009): “Ministro: «Ninguém quer que Portugal seja uma província espanhola»", 14 de Setembro.

Egea, Joaquín (2010): "Saramago y el iberismo", ABC, Sevilla, 25 de junio de 2010.

El Mundo (2003): "El Popular entra en Portugal al comprar el $75 \%$ del grupo BNC", Madrid, 10 de enero.
El País (1983a): "Lisboa y París, centros de debate sobre la crisis económica y cultural", Madrid, 14 de febrero.

El País (1983b): "Mario Soares cree que Portugal debe entrar en la CEE en el primer semestre del año pero que no ocurrirá así con España", Madrid, 10 de noviembre.

El País (1989): "Mejor amigos que hermanos", Madrid, 7 de junio de 1989.

El País (1993): “Necrológicas. Natalia Correia, escritora portuguesa”, Madrid, 17 de marzo.

El País (1995): “Muere a los 87 años Miguel Torga, patriarca de la literatura portuguesa contemporánea. Sucesor de Camoens y Pessoa, su obra fue traducida a veinte idiomas", Madrid, 18 de enero.

El País (2003a): "El trazado final del AVE Madrid-Lisboa pasará por Extremadura, tal y como quería Aznar", Madrid, 8 de noviembre.

El País (2003b): “Madrid y Lisboa estarán unidas en 2010 por tren de alta velocidad", Madrid, 7 de noviembre.

El País (2006): “Foro Digital. ¿Podrían Portugal y España forjar una alianza ibérica en el seno de la UE?", Madrid, 3 de octubre.

El País (2007): "Iberia, capital Lisboa", Madrid, 22 de julio.

El País (2008a): "El Viajero. Portugal", no 522, Madrid, 25 de octubre.

El País (2008b): “El Viajero. Portugal”, no 526, Madrid, 22 de noviembre.

El País (2011a): "La banca española arremete contra Bruselas por dudar de su solvencia", Madrid, 24 de septiembre.

El País (2011b): "Portugal suspende el proyecto AVE entre Lisboa y Madrid", Madrid, 28 de junio.

El País (2011c): "El Viajero. Extra Portugal", no 678, Madrid, 21 de octubre.

El País (2012): "João Fernandes, nuevo subdirector del Museo Reina Sofía".

Expansión (2004): “Especial Negocios Ibéricos", Madrid, 12 de noviembre.

Fernández Enguita, Mariano, Santiuste Cué, Salvador, y Hernández Bejarano, Ester (2009): El Barómetro de Opinión Hispano-Luso (BHOL), Salamanca, Centro de Análisis Sociales, Universidad de Salamanca. http://casus.usal.es/BHOL.

Fernández Navarrete, Donato (2001): “España en la Unión Europea. Antecedentes, negociaciones y consecuencias eco- 
nómicas de la integración", en AA.VV Historia de la España actual: 19392000. Autoritarismo y democracia, Madrid-Barcelona, Marcial Pons, ediciones Jurídicas y Sociales, 2aㅡ ed.

Ferro, Luis (1986): “Unánime decepción en Portugal tras la cumbre entre González y Cavaco", $A B C$, Madrid, 27 de octubre.

Fonseca, Jesús (1989): "Portugal y España: las razones de un reencuentro", $A B C$, Madrid, 7 de mayo.

Fonseca, Jesús (1990): “Amores y desamores entre Portugal y España", $A B C$, Madrid, 1 de febrero.

Franco, Enrique (1981): “Estreno del «Réquiem» de Lopes Graça en el Festival de la Costa de Estoril", El País, Madrid, 5 de agosto.

Galope, Francisco (2007): “Günter Grass: "Gosto de contar histórias mentirosas"", Visão, Lisboa, 22 de Novembro.

García Galiano, Ángel (2001): “Homo faber", Revista de libros, Madrid, no 53 , mayo.

García Pérez, Rafael (2003): “España en un mundo de cambio: a la búsqueda de la influencia internacional (1986-2002)", Pereira, Juan Carlos (coord.), La política exterior de España (1800-2003). Historia, condicionantes y escenarios, Barcelona, Ariel.

García, Javier (2001a): "La cultura de Portugal asalta España”, El País, Madrid, 11 de noviembre.

García, Javier (2001b): “Eduardo Lourenço afirma que Europa es un Estado más de EEUU", El País, Madrid, 13 de noviembre.

García, Javier (2001c): "La cultura portuguesa se aproxima a España con escritores, músicos y arte", El País, Madrid, 8 de noviembre.

García, Javier (2001d): "Madrid se prepara para mantener la segunda cita con «Perfil Portugal», $A B C$, Madrid, 19 de octubre.

García, Rocío (1995): “García Sánchez dedica su último filme al iberismo de Saramago", El País, Madrid, 15 de junio.

García-Posada, Miguel (1998): “La ética como principio creativo", El País, Madrid, 9 de octubre.

Gibson, Ian (2007): "De espaldas a Portugal", La voz de Asturias, Oviedo, 9 de diciembre.

Guardiola, Nicole (1983): “Lisboa y París, centros de debate sobre la crisis econó- mica y cultural", El País, Madrid, 14 de febrero.

Guelbenzu, José María (2001): “José María Eça de Queirós. La reliquia”, Revista de libros, Madrid, no 50, febrero.

http://www.fpa.es/es/premios-principede-asturias/premiados/1986-universidades-de-salamanca-y-coimbra. $\mathrm{htm}$ ? texto $=$ acta\&especifica $=0$

Jara, Pedro (1987): “Aparece una revista literaria, en castellano y portugués", El País, Madrid, 21 de diciembre.

Jefatura del Estado (1978): "Instrumento de Ratificación de España del Tratado de Amistad y Cooperación entre España y Portugal, hecho en Madrid el día 22 de noviembre de 1977", Boletín Oficial del Estado, $\mathrm{n}$ - 128, 30 de mayo, pp. 12443-12444.

Jefatura del Estado (1986): “Instrumento de Ratificación del Tratado hecho en Lisboa y Madrid el día 12 de junio de 1985, relativo a la adhesión del Reino de España y de la República Portuguesa a la Comunidad Económica Europea y a la Comunidad Europea de la Energía Atómica", Boletín Oficial del Estado, no 1, 1 de enero, pp. 3-687

Jorge, Lidia (2002): El jardín sin límites, Madrid, Alfaguara.

Jornal de Notícias (2006): "Espanhóis querem anexar Portugal", Lisboa, 18 de Outubro.

Juan Carlos I (1978): Palabras de Su Majestad el Rey al Presidente de Portugal Antonio Ramalho Eanes y al pueblo portugués, Guimarães, 5 de mayo. Texto íntegro: http://www.casareal.es/noticias/ news/2597-ides-idweb.html

Juan Carlos I (1989a): Palabras de Su Majestad el Rey a la Asamblea de la República de Portugal, Lisboa, 16 de mayo. Texto íntegro: http://www.casareal.es/ noticias/news/2225-ides-idweb.html

Juan Carlos I (1989b): Palabras de Su Majestad el Rey a la comunidad académica al ser investido Doctor Honoris Causa por la Universidad de Coimbra, Coimbra, 17 de mayo. Texto íntegro: http:// www.casareal.es/noticias/news/2228ides-idweb.html

Juan Carlos I (2000): Palabras de Su Majestad el Rey ante la Asamblea de la República Portuguesa, Lisboa, 12 de septiembre. Texto íntegro: http://www. casareal.es/noticias/news/649-idesidweb.html

Junta de Castilla y León (2003): Portugal en la prensa de Castilla y León. Anuario
2003, enero-junio, y julio-diciembre, 2 tomos, Junta de Castilla y León.

Junta de Castilla y León (2005): Portugal en la prensa de Castilla y León. Anuario 2005, enero-junio, y julio-diciembre, 2 tomos, Junta de Castilla y León.

Jurista, Juan Ángel (2010): "La lucidez de la prosa militante", $A B C$, Madrid, 19 de junio.

La Gaceta Regional (2004): “El hijo de Durão Barroso", Salamanca, 13 de febrero.

Landero, Luis (1991): "Recuerdos de la frontera”, El País, Madrid, 22 de junio.

Leitão, Paulo (2006): “Los vendidos”, As Beiras, Aveiro, 3 de Outubro.

Lemus, Encarnación y Pereira Castañares, Juan Carlos (2003): "Transición y política exterior (1975-1986)", en Pereira, Juan Carlos (coord.), La política exterior de España (1800-2003). Historia, condicionantes y escenarios, Barcelona, Ariel.

Llamazares, Julio (1987): "Balada de Portugal", El País, Madrid, 17 de diciembre.

Lopes, Luís Filipe de Menezes (2009): “Portugal y España”, El País, Madrid, 25 de septiembre.

M. P. (2003): "La invasión española”, El País, Madrid, 8 de noviembre.

M. R. (1989): “Unas relaciones difíciles. La mosca hispánica", El País, Madrid, 10 de enero.

Machover, Jacobo (2001): “Rompecabezas sin formas”, Revista de libros, no 50, febrero.

Marín, José María (2001a): “El primer gobierno del Partido Popular, 19962000", en Marín, José María, Molinero, Carme, e Ysàs, Pere (2001): Historia política de España 1939-2000, Madrid, ediciones Istmo.

Marín, José María (2001b): “Política exterior e integración en Europa”, en Marín, José María, Molinero, Carme, e Ysàs, Pere (2001): Historia política de España 1939-2000, Madrid, ediciones Istmo.

Márquez Reviriego, Víctor (1998): "Casa común", $A B C$, Madrid, 15 de octubre.

Martín Ferrand, M. (2010): "El iberismo como sueño", $A B C$, Madrid, 2 de julio.

Martínez i Gil, V. (1996): L'iberisme en la cultura catalana: origen i formació d'una idea político-cultural, Barcelona, Bellaterra, Publicaciones de la Universitat Autònoma de Barcelona.

Martínez Lillo, Pedro A. (2001): “La política exterior en la transición y la democracia", en AA.VV, Historia de la España actual: 1939-2000. Autoritarismo y demo- 
cracia, Madrid, Marcial Pons Ediciones Jurídicas y Sociales.

Martínez, Guillem (1999): "Entrevista: Rita da Costa. Traductora. Cataluña y Portugal tienen parecidos que no encuentras en la Península", El País, Madrid, 1 de mayo.

Martínez, Guillem (2000): "Fadomogollón”, El País, Madrid, 21 de agosto.

Mascarell, Ferrán (2007): “Nuevos y viejos catalanismos", El País, Madrid, 21 de junio.

Ministerio de Cultura (2006): "ORDEN CUL/2929/2006, de 14 de septiembre, por la que se crea el Premio "Luso-Español de Arte y Cultura» y se convoca el correspondiente a 2006, Boletín Oficial del Estado, no 230, 26 de septiembre, pp. 33761-33762.

Ministerio de Cultura (2010): "Nota conjunta de los Ministerios de Cultura de España y Portugal. El arquitecto portugués Álvaro Siza, ganador del Premio Luso-Español de Arte y Cultura", Nota de Prensa.

Molina, César Antonio (1990): Sobre el iberismo, y otros escritos de literatura portuguesa, Madrid, Akal.

Mora, Miguel (2006a): "Actualidad del ruedo ibérico", El País, Madrid, 24 de noviembre.

Mora, Miguel (2006b): “Entrevista: Eduardo Lourenço. Premio Extremadura. "¿Qué es Europa? Nada»", El País, Madrid, 6 de septiembre.

Mora, Miguel (2006c): “Un 28\% de los portugueses está dispuesto a unirse a España", El País, Madrid, 23 de septiembre.

Mora, Miguel (2007a): “Entrevista: Horacio Roque. Estrategias-Banco Internacional de Funchal. "Los portugueses somos buenos para las excusas"”, El País, Madrid, 24 de junio.

Mora, Miguel (2007b): “Portugal, ¿comunidad autónoma?", El País, Madrid, 17 de julio.

Mora, Miguel (2007c): “Saramago profetiza que Portugal y España acabarán siendo Iberia", El País, Madrid, 15 de julio.

Morales y Marín, José Luis (1985): “Portugal, tan lejos, tan cerca”, $A B C$, Madrid, 27 de julio.

Morán, Fernando (1990): España en su sitio, Barcelona, ed. Plaza \& Janés/ Cambio 16.

Moreira, José María (1991): “Entrevista con el gran poeta portugués. El iberismo in- alterable de Miguel Torga", ABC Literario, Madrid, 26 de octubre.

Moreira, José María (1993): “Muere en Lisboa a los sesenta y nueve años la poetisa portuguesa Natalia Correia", $A B C$, Madrid, 17 de marzo.

Moreira, José María (1995): “Miguel Torga: "Cuando yo muera no quiero que nadie manipule mi obra»", $A B C$, Madrid, 18 de enero.

Morodo, Raúl (1983a): “Iberismo e iberoamericanismo", El País, Madrid, 16 de julio.

Morodo, Raúl (1983b): “Nuevo hispanismo democrático", El País, Madrid, 8 de marzo.

Morodo, Raúl (1985a): “Aproximación política a Fernando Pessoa", El País, Madrid, 24 de julio.

Morodo, Raúl (1985b): “España y Portugal: distanciamiento, iberismo, cooperación", El País, Madrid, 2 de mayo.

Morodo, Raúl (1987): “Mário Soares: la política como libertad", El País, Madrid, 14 de diciembre.

Morodo, Raúl (2004): “A vueltas con el iberismo", El País, Madrid, 2 de febrero.

Morodo, Raúl (2005): Fernando Pessoa y otros precursores de las revoluciones nacionales europeas, Madrid, Biblioteca Nueva.

Pascoaes, Teixeira de (2000): Señora de la noche, Olifante, Zaragoza.

Peinado, Fernando (2009): “El 40\% de los portugueses apoya una unión política con España", El País, Madrid, 28 de julio.

Peralta García, Beatriz (2000): “El Iberismo a escena. Comedia y drama de la Unión Ibérica (1852-1890)", Carrasco González, J. M., Fernández García, Mạ J., y Leal, M. L. Trindade Madeira (Eds.), Congreso Internacional de Historia $y$ Cultura en la Frontera - I Encuentro de Lusitanistas Españoles, Tomo I, Cáceres, Universidad de Extremadura.

Peralta García, Beatriz (2008): “La imagen de Portugal en los viajeros españoles del siglo XIX", Brandenberger, Tobias, Hasse, Elisabeth, y Schmuck, Lydia (Hrgs.), A Construção do Outro: Espanha e Portugal frente a frente, Tübingen, Calepinus Verlag.

Pereira Castañares, Juan Carlos, y Martínez Lillo, Pedro A. (1998): "Política exterior, 1976-1997", Paredes, Javier, Historia contemporánea de España (siglo XX), Barcelona, Ariel.
Pérez, Claudi (2011): "Quién es el próximo", El País, Madrid, 7 de abril.

Pessoa, Fernando (2004): El banquero anarquista, Valencia, Pre-Textos.

Petschen, Santiago (2006): “El iberismo", El País, Madrid, 28 de septiembre.

Pinto, Margarida, y Egurbide, Peru (2003): "Aznar afronta su última cumbre con un Portugal en crisis y lleno de proyectos", El País, Madrid, 8 de noviembre.

Presidência do Conselho de Ministros (2011): Programa do XIX Governo Constitucional, Lisboa, 28 de Junho.

Público (2006): "Sondagem da revista espanhola Tiempo. "Quase metade dos espanhóis é favorável a uma união entre Portugal e Espanha»", Lisboa, 18 de Outubro.

Pulido, Natividad (1998): "Julio Llamazares reivindica la literatura de viajes con "Tras-os-Montes»", $A B C$, Madrid, 14 de marzo.

Queirós, J. M. Eça de (2001): La reliquia, Barcelona, Acantilado.

Queirós, José María Eça de (2003): Los Maia, Valencia, ed. Pre-Textos.

Relea, Francesc (2009): “España eclipsa a la crisis en Portugal”, El País, Madrid, 20 de septiembre.

Relea, Francesc (2011): “Los portugueses saben que los sacrificios son el billete de salida de la crisis", El País, Madrid, 1 de septiembre.

Rodríguez Rivero, Manuel (2004): “La última nación heroica”, Blanco y Negro Cultural, Madrid, 8 de mayo.

Rodríguez Zapatero, José Luís (2013): El dilema. 600 días de vértigo, Madrid, Planeta.

Royo, Sebastián (Org.) (2005): Portugal, Espanha e a integração européia: um balanço, Lisboa, Imprensa de Ciências Soaciais.

Rubert de Ventós, Xavier (1999): "Conllevando España", El País, Madrid, 8 de octubre.

Rusiñol, Pere (2005): "Portugal pierde el miedo a España", El País, Madrid, 19 de abril.

S. C. (1995): "Lisboa rinde su primer homenaje a Miguel Torga", $A B C$, Madrid, 30 de enero.

Salgado, Daniel (2007): “El escritor del otro lado", El País, Madrid, 22 de agosto.

Salvador, Gregorio (1988): "Portugal y España”, $A B C$, Madrid, 5 de marzo. 
Sampaio, Jorge (2003): Discurso do Presidente da República no Foro $A B C, M a-$ drid, 4 de Novembro. Texto íntegro: http://jorgesampaio.arquivo.presidencia.pt/pt/main.html

San Martín, Eduardo (2003): “No más de espaldas", $A B C$, Madrid, 9 de noviembre.

Saramago, José (1986): A Jangada de Pedra, Lisboa, Caminho.

Saramago, José (1987a): Historia del cerco de Lisboa, Barcelona, Seix Barral.

Saramago, José (1987b): La balsa de piedra Barcelona, Seix Barral.

Saramago, José (1990): "Mi iberismo", en Molina, César Antonio, Sobre el iberismo, y otros escritos de literatura portuguesa, Madrid, Akal.

Saramago, José (1996): Ensayo sobre la ceguera, Madrid, Alfaguara.

Saramago, José (2001): La caverna, Madrid, Alfaguara.

Saramago, José (2009): "E pur si muove”, El País, Madrid, 28 de julio.

Schwartz, Fernando (1983): "Y al Oeste, Portugal", El País, Madrid, 23 de enero.

Seco Serrano, Carlos (1998): “Cataluña y el 98", El País, Madrid, 3 de marzo.

Silva, Aníbal Cavaco (2006): Discurso do Presidente da República no Plenário do Congresso de Espanha,
Madrid, 26 de septiembre. Texto íntegro: http://www.presidencia.pt/ espanha2006/?idc=126\&idi $=1547$

Sol (2006): "Atracção por Espanha", Lisboa, 23 de Setembro.

Solano, Francisco (2000): ABC Cultural, Madrid, 29 de abril.

Teixeira, António José (2006): “Iberismo", Diário de Notícias, Lisboa, 2 de Outubro.

Telo, António José, y Torre Gómez, Hipólito de la, (2000): Portugal e Espanha nos sistema internacionais contemporâneos, Lisboa, Cosmos.

Tiempo (2006): "La Iberia deseada", Madrid, 16 de octubre.

Torre Gómez, Hipólito de la, y Telo, António José (Coords.), (2001): La mirada del otro. Percepciones luso-españolas desde la historia, Mérida, Editora Regional de Extremadura.

Trías de Bes, Josep María (1995): “El problema catalán”, $A B C$, Madrid, 7 de agosto.

Tusell, Javier (1999): Historia de España en el siglo XX. IV. La transición democrática y el gobierno socialista, Madrid, Taurus.

Unamuno, Miguel de (1989): Por Terras de Portugal e da Espanha, tradução e notas de José Bento, Lisboa, Assírio \& Alvim.

Universidad de Salamanca (1987): Acta de la sesión extraordinaria del Claustro de
Doctores celebrada el día 26 de noviembre de 1987 y Ejecución de acuerdos, Salamanca.

Velarde Fuentes, Juan (1990): "La unión económica ibérica”, $A B C$, Madrid, 28 de enero.

Venâncio, Fernando (2006): "Saramago, o Ibérico", Expresso, Lisboa, 1 de Abril.

Villena, Miguel Á. (1997): “Un iberista poco conocido en España", El País, Madrid, 13 de diciembre.

Virgílio, Bento; Jacinto, Rui Manuel Missa, et alii (Orgs.) (2005): Seminário Territórios e Culturas Ibéricas, Porto, Campo das Letras; Guarda, Centro de Estudos Ibéricos.

www.tsf.pt/Paginalnicial/Portugal/Interior. aspx? content_id=1361589\&page $=-1$ : “Politólogo José Adelino Maltez fala em "provincianismo» de jornais espanhóis na reacção às palavras de Manuela Ferreira Leite".

Yánez-Barnuevo, Juan Antonio, y Viñas, Ángel (1992): “Diez años de política exterior del gobierno socialista (19821992)", en Guerra, Alfonso, y Tezanos, José Félix (eds.), La década del cambio. Diez años de gobierno socialista 19821992, Madrid, editorial Sistema.

Yáñez, María (2007): “Portuñolismo”, El País, Madrid, 24 de julio. 